[QUERY TO AUTHOR: title and abstract rewritten by Editorial Office - not subject to change]

\title{
A transgenic mouse model reproduces human hereditary systemic
}

\section{amyloidosis.}

\section{Word count: 3986}

Michèle Chabert, PhD, affiliations: 1, 2

Xavier Rousset, $\mathrm{PhD}$, affiliation 1

Magali Colombat, MD, PhD, affiliation 3

Michel Lacasa, $\mathrm{PhD}$, affiliation 1

Hermine Kakanakou, MSc, affiliation 1

Mathilde Bourderioux, Technician, affiliation 3

Pierre Brousset, $\mathrm{MD}, \mathrm{PhD}$, affiliation 3

Odile Burlet-Schiltz, PhD, affiliation 4

Juris J. Liepnieks, $\mathrm{PhD}$, affiliation 5

Barbara Kluve-Beckerman, $\mathrm{PhD}$, affiliation 5

Gilles Lambert, HDR, PhD, affiliation 6

François P. Châtelet, MD, PhD, affiliation 1

Merrill D. Benson, $\mathrm{MD}, \mathrm{PhD}$, affiliation 5

Athina D. Kalopissis'Thèse d'Etat ès Sciences, affiliation 1

${ }^{1}$ Centre de Recherche des Cordeliers, INSERM, Sorbonne Université, Université Paris Descartes, USPC, Université Paris Diderot, Paris, France; ${ }^{2}$ EPHE PSL, Paris, France; ${ }^{3}$ Centre HospitaloUniversitaire (CHU), Département d'Anatomopathologie, Toulouse, France $;{ }^{4} \mathrm{CNRS}$, Institut de Pharmacologie et de Biologie Structurale (IPBS), Université de Toulouse, France; ${ }^{5}$ Department of Pathology and Laboratory Medicine, Indiana University School of Medicine, Indianapolis,

This is the author's manuscript of the article published in final edited form as:

Chabert, M., Rousset, X., Colombat, M., Lacasa, M., Kakanakou, H., Bourderioux, M., ... Kalopissis, A. D. (2019). A transgenic mouse model reproduces human hereditary systemic amyloidosis. Kidney International. https://doi.org/10.1016/j.kint.2019.03.013 
Indiana 46202, U.S.A; ${ }^{6}$ Inserm UMRS 1188 DéTROI, Université de La Réunion, Sainte Clotilde, France.

Michèle Chabert : present address : EPHE PSL, laboratoire CHArt, EA 4004, 4-14 rue Ferrus, 75014 Paris, France. Mail: michele.chabert@ephe.psl.eu

Xavier Rousset: present address: INOVOTION, Bât. Biopolis, 5 avenue du Grand Sablon, 38700 La Tronche, France

Corresponding author:

Athina-D. Kalopissis, Centre de Recherche des Cordeliers, 15 rue de l'Ecole de Médecine, 75006 Paris, FRANCE

Mail: athina.kalopissis@crc.jussieu.fr; ntkalopissis@orange.fr

TEL: 33961457815

The corresponding author confirms that she has had full access to the data in the study and final responsibility for the decision to submit for publication.

Funding: This work was supported by the Institut National de la Santé et de la Recherche Médicale, the Région Midi-Pyrénées, Toulouse Métropole, Fonds Européen de Développement Régional (FEDER), and the Ministère de la Recherche [Investissements d'Avenir: program PIA, ANR-10INBS08]. X. Rousset received a doctoral fellowship from the Ministère de la Recherche et Technologie (France).

Running headline: Transgenic mouse model of hereditary systemic amyloidosis 


\begin{abstract}
Amyloidoses are rare life-threatening diseases caused by protein misfolding of normally soluble proteins. The fatal outcome is predominantly due to renal failure and/or cardiac dysfunction. Because amyloid fibrils formed by all amyloidogenic proteins share structural similarity, amyloidoses may be studied in transgenic models expressing any amyloidogenic protein. Here we generated transgenic mice expressing an amyloidogenic variant of human apolipoprotein AII, a major protein of high density lipoprotein. According to amyloid nomenclature this variant was termed STOP78SERApoAII. STOP78SER-APOA2 expression at the physiological level spontaneously induced systemic amyloidosis in all mice with full-length mature STOP78SERApoAII identified as the amyloidogenic protein. Amyloid deposits stained with Congo red, were extracellular, and consisted of fibrils of approximately $10 \mathrm{~nm}$ diameter. Renal glomerular amyloidosis was a major feature with onset of renal insufficiency occurring in mice older than six months of age. The liver, heart and spleen were also greatly affected. Expression of STOP78SER$A P O A 2$ in liver and intestine in mice of the $\mathrm{K}$ line but not in other amyloid-laden organs showed they present systemic amyloidosis. The amyloid burden was a function of STOP78SER-APOA2 expression and age of the mice with amyloid deposition starting in two-month old highexpressing mice that died from six months onwards. Because STOP78SER-ApoAII conserved adequate lipid binding capacity as shown by high STOP78SER-ApoAII amounts in high density lipoprotein of young mice, its decrease in circulation with age suggests preferential deposition into preformed fibrils. Thus, our mouse model faithfully reproduces early-onset hereditary systemic amyloidosis and is ideally suited to devise and test novel therapies.
\end{abstract}

\title{
Translational Statement
}

Amyloidoses are presently incurable, with fatal outcomes at the fifth to sixth decade. We report the first animal model spontaneously developing early onset hereditary systemic amyloidosis. These transgenic mice will allow studies of the in vivo mechanisms of amyloidogenesis, which should end up in designing new treatments that attack and destroy pre-existing amyloid fibrils. These novel treatments may serve for the clinical care of all amyloidoses. In addition, they may serve to test gene-silencing therapies aiming to decrease production and plasma concentration of the amyloidogenic variant protein resulting in diminished amyloid burden and organ dysfunction, thus improving quality of life in patients.

Key words: mouse model; hereditary systemic amyloidosis; glomerular amyloid deposits 


\section{Introduction}

Amyloidoses are rare life-threatening diseases caused by protein misfolding of normally soluble proteins $^{1-4}$. The misfolded proteins aggregate into insoluble fibrils that accumulate extracellularly provoking organ dysfunction. Several criteria permitted identification of 36 amyloidogenic proteins: i) Congo red (CR) staining, the gold standard; ii) electron microscopy; iii) X-ray diffraction; iv) chemical identification of the amyloid fibril protein by sequence analysis and mass spectrometry ${ }^{2,5,6}$. In immunoglobulin light chain amyloidosis (AL), the most common form of clinical amyloidosis, amyloid fibrils are formed from monoclonal immunoglobulin light chains (LC's $)^{1-4}$; rapid and efficient treatment of the hematological disorder prolongs patient survival ${ }^{7}$. Hereditary systemic amyloidoses are autosomal dominant diseases caused by a mutation in a circulating protein that becomes amyloidogenic; the prefix $\mathrm{A}$ is added to the name of the parent protein identified in amyloid deposits, and in the ensuing amyloidosis ${ }^{2}$. Intriguingly, several hereditary amyloidoses are caused by mutations in apolipoproteins (apo), the protein moieties of lipoproteins: apoAI ${ }^{8,9}$, apoAII ${ }^{10-12}$, apoCII ${ }^{13}$, apoCIII ${ }^{14}$, and by normal apoAIV ${ }^{15}$. Thus, amyloidosis due to variant apoAII is called AApoAII amyloidosis. Reactive amyloidosis occurs under inflammatory conditions inducing overproduction of the acute phase protein serum amyloid A (SAA). Shutting down SAA synthesis by treating inflammation results in amyloid resorbtion ${ }^{16}$. Despite the great variety of amyloidogenic proteins, amyloidoses share several features: i) amyloidogenesis requires a minimal plasma concentration of the amyloidogenic protein $^{1-4}$; ii) specific proteins including glycosaminoglycans (GAG), serum amyloid Pcomponent (SAP), apoE, apoAI, apoAIV co-aggregate with the fibrils ${ }^{5,6}$; iii) all amyloid fibrils share very similar structures. Obviously, proteins with a particular tertiary structure become amyloidogenic: i.e. only a small proportion of immunoglobulin LC's is amyloidogenic ${ }^{1-4}$, and one type of murine apoAII (mApoAII) provokes amyloidosis in aged senescence-prone mice ${ }^{17-18}$. 
The fatal outcome is predominantly due to renal failure and /or cardiac dysfunction ${ }^{1-4}$, i.e. all patients with AApoAII amyloidosis ${ }^{10-12}$ and approximately $70 \%$ of patients with AL amyloidosis ${ }^{7}$ are diagnosed with nephrotic syndrome progressing to chronic kidney disease (CKD) and ultimately to end-stage renal disease (ESRD).

To study in vivo amyloidogenesis and devise novel therapies, a good animal model is needed ${ }^{19}$. In most mouse models reactive amyloidosis has been induced by repeated injections of toxic inflammatory-stimulating agents (e.g. silver nitrate, casein, lipopolysaccharide) that enhance SAA synthesis. The amyloidogenic process is accelerated by additional administration of amyloid enhancing factor (AEF, consisting of protein fibrils extracted from amyloid-laden murine tissue $)^{20,21}$. This implies a "seeding process" whereby small amounts of preformed fibrils constitute nuclei initiating amyloidogenesis ${ }^{21}$. Although amyloid deposits regress through SAA decrease, a primed state exists upon SAA reinduction ${ }^{22}$. The usefulness of such models is limited because the induction and extent of amyloid deposition are unpredictable, and the spleen is the main affected organ ${ }^{21}$ instead of the kidney in the human disease ${ }^{16}$. Transgenic mice expressing either human interleukin 6 (hIL-6) ${ }^{23,24}$ or SAA ${ }^{25}$ spontaneously displayed high SAA concentration and renal amyloidosis ${ }^{23}$. Because the renal disease became less aggressive in successive generations and fertility of transgenic mice was $l^{23}{ }^{23}$, AEF was used to induce rapid development of hepatic and splenic amyloidosis ${ }^{24}$. Transgenic mice with doxycycline-inducible SAA expression developed amyloidosis in the spleen and liver after AEF injection and independently of prior inflammation ${ }^{25}$. After doxycycline withdrawal, SAA production decreased down to normal and amyloid deposits regressed. Interestingly, reinduction of SAA overexpression resulted in rapid amyloid deposition in glomeruli leading to renal failure, while minor cardiac amyloid deposits also occurred ${ }^{25}$. Thus, current murine models overexpressing SAA rarely develop spontaneously renal amyloidosis. 
Animal models for hereditary transthyretin amyloidosis failed to reproduce familial amyloidotic polyneuropathy ${ }^{26,27}$. To our knowledge, other models of hereditary amyloidoses have not been reported. Thus, an efficient animal model of hereditary systemic amyloidosis resembling the human pathology was needed, with early onset and kidney targeting of amyloidosis. To create such a model, we chose as a transgene APOA2 carrying the STOP78 to Serine mutation resulting in production of a carboxyl terminal 21 amino acid extension of mature human apoAII (hApoAII); STOP78SER-APOA2 carriers present with systemic amyloidosis, with major amyloid deposits in kidney glomeruli provoking renal failure ${ }^{10}$. Five different single nucleotide changes resulting in four different amino acid replacements of the STOP codon, have been described in patients with the same renal amyloidosis ${ }^{10-12,28,29}$ (Supplementary Table S1). Because all amyloidogenic proteins identified thus far form amyloid fibrils with great structural similarities ${ }^{1-}$ ${ }^{4}$, transgenic mice expressing any amyloidogenic protein should be good models to study the mechanisms of amyloidogenesis and to devise and test treatments for all amyloidoses ${ }^{1-4}$. According to the established amyloid nomenclature, the hApoAII variant is termed STOP78SERApoAII in plasma and AApoAII in amyloid deposits ${ }^{2}$.

\section{RESULTS}

\section{Generation of STOP78SER-ApoAII-transgenic mice}

The STOP78SER-APOA2 transgene was obtained by site-directed mutagenesis of the 3-kilobase genomic clone of the APOA2 gene (2911/12045) comprising the endogenous promoter ${ }^{30}$ ensuring STOP78SER-ApoAII production mainly in the $\operatorname{liver}^{31}$ and a little in the intestine ${ }^{32}$

(Supplementary Figure S1). Two transgenic lines with plasma concentrations of STOP78SERApoAII either at the physiological level of normal hApoAII (K line) or 2 times higher (F line) 
spontaneously developed systemic amyloidosis. The Y line with plasma STOP78SER-ApoAII concentration 2-3 times lower than normal did not develop amyloidosis. To study solely the effects of STOP78SER-ApoAII, all lines were backcrossed onto the apoAII-knock-out (KO)/C57BL/6 background ${ }^{32,33}$. Importantly, $100 \%$ of K and F mice developed systemic amyloidosis in most organs tested (Figures 1 and 2). Hemizygous F mice (STOP78SERApoAII: $60-70 \mathrm{mg} / \mathrm{dl}$ ) and $\mathrm{K}$ mice (STOP78SER-ApoAII: 30-40 mg/dl) developed amyloidosis from 2 and 3-4 months onwards, respectively. Amyloidosis progressed more rapidly in the homozygous states, homozygous F mice often dying aged 6-7 months. Macroscopically, the liver, heart and spleen were classified in four severity stages (Supplementary Figure S2a,b), (Supplementary Table S2). The kidneys appeared normal in most mice, except in some severely affected mice where small dark-red areas suggested incomplete perfusion (Supplementary Figure S2c left).

\section{Tissue specific expression of STOP78SER-APOA2}

In K and Y mice STOP78SER-APOA2 was solely expressed in liver and intestine (Figure 3). In F mice, STOP78SER-APOA2 was highly expressed in liver and intestine, but also ectopically in kidney and, very little, in stomach. This ectopic expression may stem from random insertion of the transgene in the genome of the $\mathrm{F}$ founder mouse near a kidney-specific promoter and/or enhancer. Thus, K mice with physiological plasma STOP78SER-ApoAII concentration are good models of hereditary systemic amyloidosis since STOP78SER-ApoAII is not synthesized in kidney, heart, spleen and stomach that have substantial amyloid deposits. F mice also display systemic amyloidosis in heart and spleen that do not synthesize STOP78SER-ApoAII, whereas in kidney endogenous STOP78SER-ApoAII production may contribute to amyloid deposits.

\section{Characterization of the amyloidogenic protein:}




\section{A) At the nucleotide and amino acid levels}

DNA sequencing verified the nucleotide sequence of full-length mature STOP78SER-APOA2

(Supplementary Figure S3). Biochemical characterization of the amyloid fibril protein yielded the amino acid sequence of full-length mature STOP78SER-ApoAII (without the pre- and propeptides) including the 21 amino acid carboxyl-terminal extension. Two amino acid residues differed from normal apoAII: Ser59 (replacing Glu59) resulted from the generation of a SpeI site in Exon 4 (cf. Supplementary Methods), and Leu64 by Phe most likely from a polymerase chain reaction (PCR) anomaly during production of the transgene construct. Neither Glu59 nor Leu64 are conserved amino acids in apoAII of humans, primates, mice and rats. The presence of Ser59 and Phe64 in a different hApoAII mutant did not result in amyloidosis (A.D. Kalopissis and M. Chabert, data not shown), showing that neither amino acid was implicated in amyloidogenesis. Therefore, amyloidosis in our STOP78SER-ApoAII transgenic mice was related to the carboxyl terminal extension, which is the cause of the human disease.

\section{B) By Proteomic analysis}

Full-length mature hApoAII including the STOP to Serine mutation and the 21 amino acid carboxyl-terminal extension was identified in amyloid deposits of kidneys, liver, heart and spleen of an F mouse (Table 1), with sequence coverage from 68 to 91\% (Supplementary Figure S4). Comparably to human amyloidoses ${ }^{5,6}$, considerable amounts of apoE and lower amounts of vitronectin, clusterin, complement C3, apoB100, apoCIII, and apoAI were present in the deposits, but SAP was absent. Neither fibril-AApoAII nor fibril-associated proteins were detected in corresponding areas of Y mice.

\section{Histochemistry}


The amyloid deposits were consistently extracellular and stained with CR (Figure 1a,b) with a typical red-green birefringence observed under polarized light (Figure 1aPol.). The most affected organs were the kidneys, liver, heart, and spleen. Amyloid deposits were: i) abundant in kidney glomeruli and intertubular spaces of the F mouse, and in glomeruli of the $\mathrm{K}$ mouse; ii) greater in the liver of the F compared with the K mouse, disorganizing the plates of hepatocytes. The renal medulla was totally devoid of amyloid deposits in F and K mice (Supplementary Figure S5). Amyloidosis was never detected in any organ of Y mice (Figure 1c). Figure 2 shows extensive amyloid deposits in the F mouse, in the adrenal gland, stomach, duodenum, jejunum and ileum, and less abundant in the colon. The brain, eyes, salivary gland, lung, urinary bladder, striated muscle and testicle were devoid of amyloid fibrils, as was the ovary (not shown). The absence of amyloid in testicles and ovaries may explain the normal fertility of transgenic mice.

\section{Immunohistochemistry}

Figure 4 illustrates the increase in amyloid burden with age in $\mathrm{K}$ and $\mathrm{F}$ mice. In young mice part of STOP78SER-ApoAII (green, Figure 4a) was internalized at the apical surface of kidney proximal tubules, and part already deposited as amyloid in glomeruli and peritubular spaces (Figure 4a,c). Indeed, normal apoAII ${ }^{34}$ and apoAI ${ }^{34,35}$ are internalized in proximal tubules and degraded in lysosomes. At the intermediate and advanced stages, STOP78SER-ApoAII was not reabsorbed but formed great aggregates in glomeruli and peritubular spaces (Figure 4a,c,d). In Y mice STOP78SER-ApoAII was not retained in glomeruli and was internalized in proximal tubules; the little immunostaining is due to the very low STOP78SER-ApoAII concentration (Figure 4b).

Interestingly, mouse apoAI (mApoAI, red) was internalized at the apical surface of proximal tubules at the early (mice F1 and F2, Figure 4c) and little in advanced stage (mouse F3, Figure 
4d), whereas in some severely affected mice mApoAI was not internalized (mice F4 and F5,

\section{Figure 4d).}

At the early stage, very little amyloid deposited extracellularly along hepatocytes, cardiomyocytes, and spleen capillaries (Figure 4a). At the intermediate stage, amyloid deposits were present along large hepatic vessels and smaller ones; they were abundant between cardiomyocytes but scarce along spleen capillaries. At the advanced stage, the liver, heart and spleen were filled with amyloid deposits.

To ascertain that amyloidosis was solely due to the STOP to Serine mutation of hApoAII, parallel analyses were conducted in transgenic mice with high plasma levels of either hApoAII (Lambda, $\lambda$, line $^{30,36}$ ) or STOP78SER-ApoAII (F line). Human apoAII is synthesized in the liver of $\lambda$ mice ${ }^{30}$, catabolized in the kidney ${ }^{34}$, and present in punctate form suggesting vesicular transport. In $\lambda$ mice which never develop amyloidosis, hApoAII: was not retained in kidney glomeruli but was internalized at the apical surface of proximal tubules, essentially in the $\mathrm{S} 1$ segment adjacent to glomeruli (Figure 5a); was totally absent in the heart (Figure 5b); was present in the endoplasmic reticulum of hepatocytes near nuclei and secreted in the space of Disse (Figure 5c); was little present along some spleen capillary membranes (Figure 5d). In F mice STOP78SERApoAII formed thin/thick lines suggesting aggregates, and: accumulated in kidney glomeruli and intertubular spaces, and was not internalized in proximal tubules (Figure 5a); deposited extracellularly between cardiomyocytes and endothelial cells, forming thin or thick lines (Figure 5b); was not detected in hepatocytes but formed thick lines in the space of Disse (Figure 5c); formed abundant aggregates in extravascular spaces of the spleen red pulp (Figure 5d). The liver and spleen with extensive amyloid deposits became greatly enlarged due to their abundant capillary networks. 


\section{Electron microscopy}

In the K mouse extensive amyloid fibrils accumulated extracellularly disorganizing capillary structure (Figure 6a). The fibrils accumulated in: kidney glomeruli, between endothelial cells of capillaries and podocytes, and in intertubular spaces; the space of Disse of the liver, between hepatocytes and endothelial cells; the heart, between cardiomyocytes and endothelial cells; the extravascular space of the spleen red pulp. These organs were devoid of amyloid deposits in $\mathrm{Y}$ mice (Figure 6b). We observed typical fibrils of indeterminate length, approx. $10 \mathrm{~nm}$ in diameter, composed of twisted protofibrils ${ }^{1-4}$ (Supplementary Figure S6).

\section{Kidney dysfunction}

Y mice displayed normal renal function (Figure 7). Creatinine was significantly increased in serum and decreased in urine of $\mathrm{K}$ and $\mathrm{F}$ mice, compared with C57BL/6 mice. In serum, urea was significantly higher in F mice, while in urine it was significantly decreased in F and $\mathrm{K}$ mice compared with wild-type ones. Urinary protein concentration was significantly lower in $\mathrm{F}$ and $\mathrm{K}$ mice versus wild-type ones. Finally, the protein/creatinine ratio was significantly lower only in serum of $\mathrm{F}$ mice. Thus, glomerular amyloidosis provoked renal insufficiency as in the human disease, at ages above 6 and 5 months for $\mathrm{K}$ and $\mathrm{F}$ mice, respectively.

\section{Low-grade inflammation}

Because amyloidosis causes renal insufficiency often accompanied by inflammation ${ }^{37}$, we measured two plasma inflammation markers, CCL2/MCP1 and CXCL1/KC (Table 2). Both markers were significantly increased in $\mathrm{K}, \mathrm{F}$, and even in $\mathrm{Y}$ mice, as compared with mice without amyloidosis (KOAII, and lines $\beta, \delta, \lambda$ expressing $A P O A 2^{30,33,34,36}$ ). CCL2/MCP-1 is increased in hemodialysis patients, far above the values of $\mathrm{Y}, \mathrm{K}$, and F mice ${ }^{38}$. The low-grade inflammation of 
$\mathrm{K}$ and $\mathrm{F}$ mice may be related to kidney dysfunction due to amyloidosis, and that of $\mathrm{Y}$ mice to the presence of STOP78SER-ApoAII.

\section{STOP78SER-ApoAII in plasma and high density lipoprotein}

Plasma STOP78SER-ApoAII did not decrease with age in Y mice, but drastically decreased in K and F mice (Figure 8), suggesting STOP78SER-ApoAII deposition into amyloid fibrils the amounts of which increased with age (Figure 4).

Because apoAII is an apolipoprotein of high density lipoprotein (HDL), we analyzed HDL apolipoprotein compositions of five patients with AApoAII amyloidosis ${ }^{10-12}$. STOP78SERApoAII conserves Cys6 and forms a 20 kDa-homodimer ${ }^{39}$ (Figure 9a,b). The patient's HDL carried similar amounts of dimers $17 \mathrm{kDa}-\mathrm{hApoAII}$ and 18.5 kDa-STOP78SER-

ApoAII/hApoAII, but trace amounts of $20 \mathrm{kDa}$-STOP78SER-ApoAII. To determine whether STOP78SER-ApoAII has a diminished lipid binding capacity, we analyzed HDL-STOP78SERApoAII contents of K and F mice aged 4 to 7 months (Figure 9c). In young K mice, HDL carried high STOP78SER-ApoAII amounts, whereas in 7-month-old mice STOP78SER-ApoAII decreased and apoAI was the major apolipoprotein, as in normal humans and mice. In F mice aged 4 and 5 months, HDL carried high STOP78SER-ApoAII amounts, whereas at 6 and especially 7 months, STOP78SER-ApoAII decreased and apoAI was the major apolipoprotein. The observation that HDL of young K and F mice carried high amounts of STOP78SER-ApoAII clearly indicates that STOP78SER-ApoAII conserved adequate lipid binding properties. Thus, the age dependent decrease of STOP78SER-ApoAII in HDL (Figure 9) and serum (Figure 8) is probably related to preferential deposition of STOP78SER-ApoAII onto preformed amyloid fibrils. HDL of Y mice carried low STOP78SER-ApoAII amounts, as expected from its low plasma concentration (Figure 9b,d). 


\section{DISCUSSION}

We report a novel transgenic mouse model of human hereditary systemic amyloidosis due to circulating STOP78SER-ApoAII, with the kidneys the major affected organs. Amyloid fibrils deposited primarily in renal glomeruli and peritubular spaces but not in medullary interstitium, comparably to the human disease ${ }^{10-12}$ and unlike AApoCII ${ }^{13}$ and AApoAIV ${ }^{15}$ amyloidoses. Renal insufficiency was observed in transgenic mice at ages above 5-6 months. The physiological plasma STOP78SER-ApoAII concentration of hemizygous K mice was sufficient to induce amyloidosis, as in the human disease ${ }^{10-12}$. K mice express STOP78SER-APOA2 only in the liver and intestine, and not in the kidney, heart and spleen with heavy amyloid burden. Moreover, the amyloid fibril protein was the secreted form of full-length mature STOP78SER-ApoAII (without the pre- and pro-peptides), as in human patients ${ }^{10-12}$. Thus, K mice are an appropriate model of hereditary systemic amyloidosis.

The deposits also contained fibril-associated proteins as in human biopsies (apoE, apoAI, apoCIII, apoB, vitronectin, clusterin) with the exception of $\mathrm{SAP}^{5,6}$. The role of these proteins is unknown, but they are not necessary for amyloidogenesis since mice deficient in $\mathrm{SAP}^{40}$, apoE $\mathrm{E}^{41,42}$ or apoAI ${ }^{42}$ develop amyloidosis. SAP is an acute phase reactant in mice ${ }^{43}$, and is indeed present in transgenic mice with high SAA expression ${ }^{24}$. The absence of SAP in amyloid fibrils of our STOP78SER-ApoAII-transgenic mice could stem from the lack of high inflammatory state. Indeed, our mice displayed low-grade inflammation (shown by the small elevation of inflammation markers CCL2/MCP1 and CXCL1/KC), possibly representing a compensatory response to amyloidosis.

Patients with AApoAII amyloidosis have proteinuria, azotemia and finally renal failure, in the fifth/sixth decade ${ }^{10-12}$, but serum and urine parameters have been reported for very few patients. 
In transgenic mice above 6 months of age, creatinine significantly increased in the serum and decreased in the urine, indicating onset of renal insufficiency. Notably, F mice with higher STOP78SER-APOA2 expression were more affected than K mice. However, transgenic mice did not display proteinuria, and urinary protein concentration was lower than in controls. A possible explanation is that glomerular filtration was progressively blocked by increasing amyloid deposits with age. This is corroborated by decreased internalization of apoAI in kidney proximal tubules in older mice, and absence of apoAI in two severely affected 7 month-old F mice (Figure 4d). A limitation of this study is that our transgenic lines are congenic, not co-isogenic, to C57BL/6 due to backcrossing to the KOAII/C57BL6 background, and thus contain portions of chromosome 1, surrounding the targeted mouse Apoa2 locus, which are still 129S4/SvJae ${ }^{32,44-46}$. Therefore, we cannot exclude that passenger mutations may contribute to the kidney dysfunction of $\mathrm{F}$ and $\mathrm{K}$ mice. Furthermore, the four groups of mice were not totally matched in age, with a higher percentage of older mice in $\mathrm{F}$ and $\mathrm{Y}$ lines.

The decrease in sera and HDL of STOP78SER-ApoAII as a function of age raised the question of a diminished lipid binding capacity. However, HDL of young K and F mice carried high STOP78SER-ApoAII amounts, the STOP78SER-ApoAII-HDL amount decreasing in older mice. Therefore, STOP78SER-ApoAII conserves adequate lipid binding capacity. Probably, part of newly secreted STOP78SER-ApoAII rapidly aggregates onto amyloid fibrils in young mice, while another part associates with HDL and remains in the circulation. Later in life, increasing amounts of newly secreted STOP78SER-ApoAII are preferentially driven into preformed fibrils, in accord with the "seeding process" theory. Similar decreases in the serum concentration of amyloidogenic apolipoproteins have been described in patients with hereditary systemic amyloidosis due to the variants apoAI-Iowa ${ }^{47}$ and apoCIII-D25 $\mathrm{V}^{14}$. 
The molecular mechanism(s) of amyloid formation and its determinants are largely unknown. An established concept is initiation of protein misfolding by short 4- to 10-residue segments, termed amyloid "hot spots", with high propensity for $\beta$-aggregation. By use of the consensus prediction algorithm AMYLPREP2 ${ }^{48}$ hApoAII was shown to have two amyloid "hot spots" in residues 1018 and $60-70^{49}$. However, hApoAII is not amyloidogenic in humans and transgenic mice (Figure 5). The additional "hot spot" in residues 79-87 of the C-terminal extension ${ }^{49}$ of STOP78SERApoAII may trigger amylogenicity. Contrary to hApoAII, type C mApoAII is amyloidogenic in its mature and pro-apoAII forms in senescence-prone mice, with an autosomal recessive transmission ${ }^{17,18}$. Murine apoAII was predicted to have two major amyloid "hot spots" in residues 6-16 and $48-65^{49}$. The difference in amyloidogenicity between mApoAII and hApoAII is unexplained at present. Interestingly, $\mathrm{AApoAI}^{8}$, $\mathrm{AApoAII}^{10-12,28,29}$, and $\mathrm{AApoCIII}{ }^{14}$ amyloidoses are caused by some full-length variant proteins, or by peptides issued from some proteins by protease cleavage (i.e. several amino-terminal peptides of apoAI ${ }^{8,9}$, and the amino-terminal amino acid-peptide of $\mathrm{SAA}^{50}$ ).

In conclusion, expression of STOP78SER-APOA2 with a carboxyl terminal, 21 amino acid extension is the obvious cause of amyloidosis in our transgenic mice. $\mathrm{K}$ mice display systemic amyloidosis, since STOP78SER-ApoAII is produced in the liver and intestine and not in tissues with great amyloid deposits such as kidney, heart and spleen, and amyloid deposits contain the secreted STOP78SER-ApoAII form. Despite ectopic STOP78SER-APOA2 expression in kidneys, F mice with higher plasma STOP78SER-ApoAII concentration develop amyloidosis early in life and may serve to test new therapeutic molecules. The absence of amyloidosis in low-expressing Y mice suggests a threshold for aggregation and fibrillogenesis, and justifies therapies using gene-silencing therapies to lower production of amyloidogenic proteins ${ }^{51,52}$. This novel mouse 
model of hereditary systemic amyloidosis faithfully reproducing the human pathology ${ }^{10-12,28,29}$ with the additional advantages of early onset of amyloidosis and great fertility should be very useful to researchers. Importantly, the great structural similarity of amyloid fibrils formed by all amyloidogenic proteins ${ }^{1-4}$ opens the way to usage of this model to study in vivo amyloid formation and to devise and test treatments for all amyloidoses.

\section{METHODS}

\section{Generation and maintenance of transgenic mice}

The generation, maintenance and identification of the three transgenic lines $\mathrm{Y}, \mathrm{K}$ and $\mathrm{F}$ are described in Supplementary Methods.

The procedures followed were in accordance with institutional regulations for the care and use of laboratory animals. The Ethics Committee gave favorable opinions \#Ce5/2012/028 and APAFIS\#6010-2016070718347485 v3. All transgenic lines have been deposited at the MIGRATECH® database of Inserm (Institut National de la Santé et de la Recherche Médicale) with the following numbers: MT0564, Mouse models of Amyloidosis for STOP78SER-ApoAIItransgenic mice, and MTO513, MTO502, MTO471, ApoA2-humanized transgenic mice.

Amyloid fibril extraction and biochemical analysis of amyloid protein, Direct DNA Sequence Analysis, RNA extraction and Real time-polymerase chain reaction, Blood sampling and biochemical analyses, Immunohistochemistry, Electron microscopy See Supplementary Methods

Tissue sampling and histological analyses 
Following blood drawing, intracardiac vascular washing was performed with $20 \mathrm{ml} 0.1 \mathrm{M}$ phosphate buffer (PB) and then with $15 \mathrm{ml} 4 \%$ paraformaldehyde (PFA) in $0.1 \mathrm{M} \mathrm{PB}$. The tissues were quickly removed, rinsed in $\mathrm{PB}$, and cut.

Details for CR staining and immunohistochemistry are in Supplementary Methods.

\section{Mass spectrometry-based proteomic analysis}

Proteomic analyses were performed in kidney, liver, heart and spleen of one $\mathrm{F}$ and one $\mathrm{Y}$ mouse aged 7 months. Proteins were extracted from amyloid deposits identified by CR staining and laser microdissected. Tryptic peptides were separated by nano-liquid chromatography coupled to nanospray ionisation tandem mass spectrometry; proteins were identified by searching mouse protein database (SwissProt) with experimental data using Mascot. Search for STOP78SERApoAII required that the sequence be incorporated into the database. The spectral count metric used to rank the proteins according to their relative abundance in the sample corresponds to the spectral count values from Proline software.

Details are in Supplementary Methods

\section{Lipoproteins and apolipoproteins}

Lipoproteins were prepared from pooled sera from at least 10 mice/group, supplemented with $0.005 \%$ gentamycin $/ 1 \mathrm{mM}$ EDTA/0.04\% Na-azide, $0.02 \%$ merthiolate and protease inhibitors, and subjected to sequential ultracentrifugations ${ }^{53}$. Details of ultracentrifugation conditions, SDSPAGE and Western blotting of HDL from patients and transgenic mice are in Supplementary Methods.

\section{Statistical analysis}


Statistical calculations were carried out using GraphPad Prism 5.02. The statistical tests used for each experiment are indicated in the legend of the corresponding table or figure. $P$ values $<0.05$ were considered statistically significant. 


\section{DISCLOSURE}

The authors declare no competing financial interests.

\section{ACKNOWLEDGEMENTS}

We acknowledge the financial supports of Inserm and the Région Midi-Pyrénées, Toulouse Métropole, Fonds Européen de Développement Régional (FEDER), and the «Investissements d'Avenir » program (PIA, ANR-10-INBS08) of the Ministère de la Recherche for mass spectrometry equipment and bioinformatics at IPBS. X. Rousset received a doctoral fellowship from the Ministère de la Recherche et Technologie (France).

We acknowledge excellent technical help of Carole Lasne (CRC) for generation of transgenic mice and blood collections, Pierre-Etienne Bouchet for immuno-histological preparations, Danielle Pastier for biochemical characterization of lipoproteins and apolipoproteins, Marie Cortese and the Centre de Microscopie Electronique Appliquée à la Biologie (CMEAB, Université de Toulouse, France), Nicolas Claverie, Marylène Guedes, Davy Laporte, Flavien Normandin and Isabelle Primout for histological preparations.

We are most grateful for excellent technical assistance of the team of our animal facility (Centre d'Explorations Fonctionnelles, CEF) of the Centre de Recherche des Cordeliers (CRC), Paris, France. We are indebted to the Center of Histology, Imaging and Cytometry (CHIC) of CRC and especially to Christophe Klein for help with confocal microscopy.

Special thanks to Tessa Fredriksen for help with the RNA extraction and to Agnès Ribeiro and Véronique Carrière for helpful discussions.

\section{AUTHOR CONTRIBUTIONS}

A.D.K. conceived the generation of STOP78SER-ApoAII-transgenic mice, initiated and supervised studies and coordinated collaborations. 
M.L. and X.R. conceived and performed site-directed mutagenesis and obtained the construct of STOP78SER-APOA2.

A.D.K. and M.Ch. performed blood and urine collections, intracardiac perfusions of mice, tissue collections, macroscopic observations, discussed and interpreted the results and wrote the paper. M.D.B. provided patient sera and characterized amyloid deposits.

X.R. and M.Ch. performed ultracentrifugations of sera and biochemical analyses of lipoproteins. F.P.C. performed intracardiac perfusions of mice, tissue collections, confocal microscopy of immunostained tissues and interpreted microscopy data.

M.Co. and M.B. performed histological preparations, Congo red staining, ultrastructural analyses, proteomic analyses, and interpreted the data.

H.K. determined tissue specific expression of STOP78SER-APOA2.

O.B.-S. provided access to the proteomic infrastructure of IPBS of Universite de Toulouse, helped with the statistical treatment and interpreted the results of the proteomic analyses.

G.L. performed the assays of plasma inflammation markers and discussed the results.

P.B. discussed the results.

J.J.L. performed amino acid sequencing of amyloid fibril protein.

B.K.B. performed isolation and fractionation of amyloid fibril protein.

All co-authors carefully read the paper. 


\section{SUPPLEMENTARY MATERIAL}

\section{Supplementary Methods}

Generation and maintenance of transgenic mice

Amyloid fibril extraction and biochemical characterization

Direct DNA sequence analysis

RNA extraction and RT-PCR

Blood and urine sampling and biochemical analyses

Immunohistochemistry

Electron microscopy

Mass spectrometry-based proteomic analysis

Lipoproteins and apolipoproteins

\section{Supplementary Figures}

Figure S1. Generation of pUC-APOA2 with the STOP to SER mutation.

Step 1: Generation of pUC19-Exon 4 SpeI

Step 2: Generation of pUC19-Exon 4 Stopless

Step 3: Generation of full-length pUC19-STOP78SER-APOA2

Abbreviation: E1 to E4: Exons 1 to 4.

Figure S2. Macroscopic alterations of organs due to amyloidosis.

The kidneys (K), liver (L), heart (H) and spleen (S) of 7 month-old wild-type C57BL/6 and hemizygous F mice were photographed following intracardiac washing. (a) The four organs from a C57BL/6 (left) and an F mouse (right). (b) The four organs from two F mice. (c) Enlargement of the kidneys of the two F mice in (b). Note that the liver, heart and spleen of transgenic mice were larger and the liver often distorted, as compared to the same organs of the wild-type mice. 
In most cases, the kidneys of transgenic mice appeared normal, as in (a) and (b) on the right. In very few mice, one or both kidneys displayed small dark areas suggesting incomplete perfusion, as the left kidney in (b).

Figure S3. Nucleotide and amino acid sequences of full-length AApoAII in amyloid deposits.

The genomic DNA was extracted from splenic tissue and exons 3 and 4 of the AAPOA2 gene were directly sequenced. Amyloid fibrils were extracted from tissues of $\mathrm{K}$ and $\mathrm{F}$ mice and biochemically characterized. These analyses revealed the amino acid sequence of full-length $A A P O A 2$ cDNA with the 21 amino acid carboxyl terminal extension. The protein sequence is presented in single letter code below each codon. Two amino acid residues differed from the normal hApoAII sequence: Glu59 was replaced by Ser59 by site directed mutagenesis in order to generate a SpeI site. The substitution of Leu64 by Phe64 was probably due to a PCR anomaly, which occurred during production of the transgenic construct. The STOP78 to SER mutation was obtained by generation of a restriction site for $S a c I$, so that the STOP codon TGA was mutated to AGC coding for SER78, while CTC coded for the following SER79.

The modified nucleotides are represented in blue, and the modified amino acids in red. The red lines indicate the tryptic peptides that were sequenced; the green lines are tryptic peptides found in the same digest and found to overlap the other sequences. The pre- and pro-peptide were not found in AApoAII of any amyloid deposits since they were cleaved by specific proteases: the prepeptide cotranslationally, and the propeptide just after secretion ${ }^{\mathrm{S}}$.

\section{Figure S4. Sequence coverage of AApoAII in proteomic analysis of amyloid fibrils.}

Mass spectrometry-based proteomic analyses were performed in kidney, liver, heart and spleen of one $\mathrm{F}$ and one $\mathrm{Y}$ mouse aged 7 months. An area of $150000 \mu \mathrm{m} 2$ of congophilic amyloid deposits was selected by laser microdissection for each organ of F mice. Y mice which do not develop 
amyloidosis served as a control, and comparable areas were dissected from each organ. Proteins were extracted, digested into tryptic peptides, and separated by nano-liquid chromatography coupled to nanospray ionisation tandem mass spectrometry. The amino acid sequence of the preand pro-peptide of hApoAII and AApoAII (a total of 23 amino acids) is highlighted in turquoise, and was not taken into account for the calculation of the sequence coverage. Indeed, the pre- and pro-peptides are hydrolyzed by intracellular and extracellular proteases, respectively, and only the mature hApoAII (77 amino acids) or STOP78SER-ApoAII (98 amino acids) are secreted by hepatocytes ${ }^{\mathrm{S}}$.

The 21 amino acid extension of AApoAII is highlighted in yellow, and the sequence coverage in red bold type.

\section{Figure S5. Absence of amyloid deposits in renal medulla.}

The kidneys were obtained from the same 7 month-old F, K and Y mice described in Figure 1.

Ten $\mu$ m-thick kidney sections were stained with Congo red (CR), counterstained with hematoxylin/eosin, and viewed by optical microscopy and under strong polarized light. Characteristic images of optical microscopy are shown. Images under polarized light were negative and are not shown.

In the photomicrograph of the $\mathrm{K}$ mouse the cortex, medulla and papilla are indicated by dashed lines drawn across each area.

C cortex; DT, distal tubule; H, loop of Henle; M, medulla; P, papilla; PT, proximal tubule Scale $=100 \mu \mathrm{m}$

\section{Figure S6. Typical amyloid fibrils in liver and spleen.}

The liver and spleen of the 7 month-old K mouse (shown in Figure 2) were viewed by electron microscopy at 10000 magnification. Extracellular amyloid deposits appeared as rigid non- 
branching, randomly arranged fibrils ranging from 8 to $11 \mathrm{~nm}$ in external diameter. Fibrils were twisted and of indeterminate length.

\section{SUPPLEMENTARY TABLES}

Table S1. Amyloidogenic human apolipoprotein AII mutations

Table S2. Classification of macroscopic alterations of organs from STOP78SER-ApoAIItransgenic mice

Supplementary material is linked to the online version of the paper at www.kidneyinternational.org. 


\section{REFERENCES}

1. Pepys MB. Amyloidosis. Annu Rev Med. 2006;57:233-241.

2. Sipe JD, Benson MD, Buxbaum JN, et al. Amyloid fibril proteins and amyloidosis: chemical identification and clinical classification International Society of Amyloidosis 2016 Nomenclature Guidelines. Amyloid. 2016;23:209-213.

3. Merlini G, Bellotti V. Molecular mechanisms of amyloidosis. N Engl J Med. 2003;349:583596.

4. Gillmore JD, Hawkins PN. Pathophysiology and treatment of systemic amyloidosis. Nat Rev Nephrol. 2013;9:574-586.

5. Vrana JA, Gamez JD, Madden BJ, et al. Classification of amyloidosis by laser microdissection and mass spectrometry-based proteomic analysis in clinical specimens. Blood. 2009;114:4957-4959.

6. Lavatelli F, Vrana JA. Proteomic typing of amyloid deposits in systemic amyloidosis. Amyloid. 2011;18:177-182.

7. Rezk T, Lachmann HJ, Fontana M, et al. Prolonged renal survival in light chain amyloidosis: speed and magnitude of light chain reduction is the crucial factor. Kidney Intern 2017; 92:1476-1483.

8. Rowczenio D, Dogan A, Theis JD, et al. Amyloidogenicity and clinical phenotype associated with five novel mutations in apolipoprotein A-I. Am J Pathol. 2011;179:1978-1987.

9. Louros NN, Tsiolaki PL, Griffin MDW, et al. Chameleon "aggregation-prone" segments of apoA-I: a model of amyloid fibrils formed in apoA-I amyloidosis. Int J Biol Macromol. 2015;79:711-718.

10. Yazaki M, Liepnieks JJ, Yamashita T, et al. Renal amyloidosis caused by a novel stop-codon mutation in the apolipoprotein A-II gene. Kidney Intern. 2001;60:1658-1665. 
11. Benson MD, Liepnieks JJ, Yazaki M, et al. A new human hereditary amyloidosis: the result of a stop-codon mutation in the apolipoprotein AII gene. Genomics. 2001;72:272-277.

12. Yazaki M, Liepnieks JJ, Barats MS, et al. Hereditary systemic amyloidosis associated with a new apolipoprotein AII stop codon mutation Stop78Arg. Kidney Intern. 2003;64:11-16.

13. Nasr SH, Dasari S, Hasadsri L, et al. Novel type of renal amyloidosis derived from apolipoprotein-CII. J Am Soc Nephrol. 2017;28:439-445.

14. Valleix S, Verona G, Jourde-Chiche N, et al. D25V apolipoprotein C-III variant causes dominant hereditary systemic amyloidosis and confers cardiovascular protective lipoprotein profile. Nat Commun. 2015;DOI: 10.1038/ncomms10353.

15. Dasari S, Amin MS, Kurtin PJ, et al. Clinical, biopsy, and mass spectrometry characteristics of renal apolipoprotein AIV amyloidosis. Kidney Intern. 2016;90:658-664.

16. Gillmore JD, Lovat LB, Persey MR, et al. Amyloid load and clinical outcome in AA amyloidosis in relation to circulating concentration of serum amyloid A protein. The Lancet. 2001;358:24-29.

17. Higuchi K, Kitagawa K, Naiki H, et al. Polymorphism of apolipoprotein A-II (apoA-II) among inbred strains of mice. Relationship between the molecular type of apoA-II and mouse senile amyloidosis. Biochem J. 1991;279:427-433.

18. Higuchi K, Kogishi K, Wang J, et al. Accumulation of pro-apolipoprotein A-II in mouse senile amyloid fibrils. Biochem J. 1997;325:653-659.

19. Buxbaum JN. Animal models of human amyloidoses: are transgenic mice worth the time and the trouble? FEBBS Lett. 2009;583:2663-2673.

20. Gruys E, Snell FWJJ. Animal models for reactive amyloidosis. Baillère's Clin. Rheumatol. 1994;8:599-611. 
21. Lundmark K, Westermark GT, Nyström S, et al. Transmissibility of systemic amyloidosis by a prion-like mechanism. Proc Natl Acad Sci. 2002;99:6979-6984.

22. Hawkins PN, Pepys MB. A primed state exists in vivo following histological regression of amyloidosis. Clin Exp Immunol. 1990;81:325-328.

23. Solomon A, Weiss DT, Schell M, et al. Transgenic mouse model of AA amyloidosis. Am J Pathol. 1999;154:1267-1272.

24. Wall JS, Kennel SJ, Paulus MJ, et al. Quantitative high-resolution microradiographic imaging of amyloid deposits in a novel murine model of AA amyloidosis. Amyloid. 12, 149$156(2005)$.

25. Simons JP, Al-Shawi R, Ellmerich S, et al. Pathogenetic mechanisms of amyloid A amyloidosis. Proc Natl Acad Sci. 2013;110:16115-16120.

26. Kohno K, Palha JA, Miyakawa K, et al. Analysis of amyloid deposition in a transgenic mouse model of homozygous familial amyloidotic polyneuropathy. Am J Pathol. 1997; 150:1497-1508.

27. Ueda M, Ando Y, Hakamata Y, et al. A transgenic rat with the human ATTR V30M: a novel tool for analyses of ATTR metabolisms. Biochem Biophys Res Commun. 2007;352:299-304.

28. Connors LH, Prokaeva T, Akar H, et al. Familial amyloidosis: recent novel and rare mutations in a clinical population. In: Grateau G, Kyle RA, Skinner M, eds. Amyloid and Amyloidosis. CRC Press; 2005:360.

29. Rowczenio D, Gilbertson JA, Bybee A, et al. Hereditary amyloidosis in a Spanish family associated with a novel non-stop mutation in the gene for apolipoprotein AII. In: Grateau G, Kyle RA, Skinner M, eds. Amyloid and Amyloidosis. CRC Press; 2005:366. 
30. Boisfer E, Lambert G, Atger V, et al. Overexpression of human apolipoprotein A-II in mice induces hypertriglyceridemia due to defective very low density lipoprotein hydrolysis. J Biol Chem. 1999;274:11564-11572.

31. Hussein MM, Zannis VI. Intracellular modification of human apolipoprotein A-II (ApoAII) and sites of ApoAIImRNA synthesis: Comparison of ApoAII with Apo CII and ApoCIII isoproteins. Biochemistry. 1990;29:209-217.

32. Weng W, Breslow JL. Dramatically decreased high density lipoprotein cholesterol, increased remnant clearance, and insulin hypersensitivity in apolipoprotein A-II knockout mice suggest a complex role for apolipoprotein A-II in atherosclerosis susceptibility. Proc Natl Acad Sci. USA. 1996;93:14788-14794.

33. Dugué-Pujol S, Rousset X, Pastier D, et al. Human apolipoprotein A-II associates with triglyceride-rich lipoproteins in plasma and impairs their catabolism. J Lipid Res. 2006;47:2631-2639.

34. Dugué-Pujol S, Rousset X, Château D, et al. Apolipoprotein A-II is catabolized in the kidney as a function of its plasma concentration. J Lipid Res. 2007;48:2151-2161.

35. Kozyraki R, Fyfe J, Kristiansen M, et al. The intrinsic factor-vitamin $\mathrm{B}_{12}$ receptor, cubilin, is a high-affinity apolipoprotein A-I receptor facilitating endocytosis of high-density lipoprotein. Nat Med. 1999;5:656-661.

36. Pastier D, Dugué S, Boisfer E, et al. Apolipoprotein A-II/AI ratio is a key determinant in vivo of HDL concentration and formation of pre- $\beta$ HDL containing apolipoprotein AII. Biochemistry. 2001;40:12243-12253.

37. Suarez-Alvarez B, Liapis H, Anders H-J. Links between coagulation, inflammation, regeneration, and fibrosis in kidney pathology. Lab Invest. 2016;96:378-390. 
38. Papayanni A, Alexopoulos E, Giamalis P et al. Circulating levels of ICAM-1, VCAM-1, and MCP-1 are increased in haemodialysis patients: association with inflammation, dyslipidemia, and vascular events. Naphrol Dial Transplant. 2002;17:435-441.

39. Brewer HB Jr, Lux SE, Ronan R, John KM. Amino acid sequence of human apoLp-Gln-II (apoA-II), an apolipoprotein isolated from the high-density lipoprotein complex. Proc Nat Acad Sci USA 1972;69:1304-1308.

40. Botto M, Hawkins PN, Bickerstaff MC, et al. Amyloid deposition is delayed in mice with targeted deletion of the serum amylod P component gene. Nature Med. 1997;3:855-859.

41. Hoshii Y, Kawano H, Cui D, et al. Amyloid A protein amyloidosis induced in apolipoprotein E-deficient mice. Am J Pathol. 1997;151:911-917.

42. Elliot-Bryant R, Cathcart ES. Apolipoprotein E and apolipoprotein A-I knock-out mice readily develop amyloid A protein amyloidosis. Clin Immunol Immunopathol. 1997;85:104108.

43. Pepys MB, Baltz M, Gomer K, et al. Serum amyloid P-component is an acute-phase reactant in the mouse. Nature 1979;278:259-261.

44. Smithies O, Maeda N. Gene targeting approaches to complex genetic diseases: Atherosclerosis and essential hypertension. Proc Natl Acad Sci. 1995;92:5266-5272.

45. Gerlai R. Gene targeting: technical confounds and potential solutions in behavioral brain research. Behav Brain Res. 2001;125:13-21.

46. Vanden Berghe T, Hulpiau P, Martens L, et al. Passenger mutations confound interpretation of AII genetically modified congenic mice. Immunity 2015;43:200-209.

47. Rader DJ, Gregg RE, Meng MS, et al. In vivo metabolism of a mutant apolipoprotein AIIowa, associated with hypoalphalipoproteinemia and hereditary systemic amyloidosis. J Lipid Res. 1992;33:755-763. 
48. Tsolis AC, Papandreou NC, Iconomidou VA, et al. A consensus method for the prediction of ‘aggregation-prone” peptides in globular proteins. PLoS One. 2013;8(1):e54175.

49. Gurski O. Hot spots in apolipoprotein A-II misfolding and amyloidosis in mice and men. FEBS Lett. 2014;588:845-850.

50. Uhlar CM, Whitehead AS. Serum amyloid A, the major vertebrate acute-phase reactant. Eur J Biochem. 1999;265:501-523.

51. Adams D, Gonzalez-Duarte A, O’Riordan W.D, et al. Patisiran, an RNAi therapeutic, for hereditary transthyretin amyloidosis. N Engl J Med. 2018;379:11-21.

52. Benson MD, Waddington-Cruz M, Berk JL, et al. Inotersen treatment for patients with hereditary transthyretin amyloidosis. N Engl J Med. 2018;379:22-31.

53. Havel RJ, Eder HA, Bragdon JH. The distribution and chemical composition of ultracentrifugally separated lipoproteins in human serum. J Clin Invest. 1955;34:1345-1353. 


\section{FIGURE LEGENDS}

\section{Figure 1. Major amyloid deposits in kidney, liver, heart and spleen}

Several tissues were prepared from hemizygous 7 month-old mice (4 F, $4 \mathrm{~K}$ and $4 \mathrm{Y}$ mice) as described in Methods under “Tissue sampling and biological analyses". Macroscopically, the following stages were observed: i) F mice: heart 3 or 4, liver 4, spleen 4; ii) K mice: heart 2 or 3 or 4, liver 3 or 4, spleen 3; iii) Y mice: heart 0, liver 0, spleen 0. As explained in Supplementary Figure S2, the kidneys of the above mice had a normal appearance: stage 0 .

Ten $\mu$ m-thick sections of kidney, liver, heart, and spleen were stained with Congo red (CR), counterstained with hematoxylin/eosin, and viewed by optical microscopy and under strong polarized light (Pol.). Characteristic images of one F (heart 3, liver 4, spleen 4), one K (heart 3, liver 3, spleen 4), and one Y mouse are shown. (a) F mouse; (b) K mouse; (c) Y mouse, devoid of amyloid deposits.

All photomicrographs contain scale bars. Arrowheads depict amyloid deposits.

\section{Figure 2. Amyloid deposits in several organs}

Ten $\mu \mathrm{m}$-thick sections of organs from three 7 month-old F mice (the same as in Figure 1) and one K mouse (also studied in Figure 1), were stained with Congo red (CR), counterstained with hematoxylin/eosin, and viewed by optical microscopy. Characteristic images of one F mouse (heart 3, liver 4, spleen 4) are shown. (a) Organs with amyloid deposits; (b) Organs without amyloid deposits.

All photomicrographs contain scale bars. Arrowheads depict amyloid deposits.

\section{Figure 3. Tissue specific expression of STOP78SER-APOA2}

Total RNA was extracted from 8 tissues of 4 month-old F, K, Y expressing STOP78SER-APOA2, and KOAII mice not expressing STOP78SER-APOA2. After reverse-transcription to cDNA, 
STOP78SER-APOA2 cDNA was amplified by PCR. The length of PCR products is $177 \mathrm{bp}$, showing absence of contamination of mRNAs by genomic DNA. STOP78SER-APOA2 mRNAs are present in the liver and intestine of $\mathrm{Y}, \mathrm{K}$, and $\mathrm{F}$ mice, but not in tissues of KOAII mice used as negative controls. Ectopic expression of STOP78SER-APOA2 was detected in the kidney of F mice, and a very small one in the stomach.

\section{Figure 4. Aggravation of amyloidosis with age}

The kidneys, liver, heart and spleen were prepared from hemizygous $\mathrm{F}$ and $\mathrm{K}$ mice at ages 2, 5, 7 or 8 months (three $\mathrm{F}$ and three $\mathrm{K}$ mice at each age), and from three 7 month-old $\mathrm{Y}$ mice. The tissue preparations are described in Methods under "Tissue sampling and biological analyses". Macroscopically, the following stages were observed: i) 2 month-old $\mathrm{F}$ and 3 month-old $\mathrm{K}$ mice: heart 0 , liver 0 , spleen 0 ; ii) 5 month-old F mice: heart 2 or 3 , liver 2 or 3 , spleen 3 ; iii) 5 monthold K mice: heart 1 or 2 or 3, liver 2 or 3, spleen 2 or 3; iv) 7 month-old F mice: heart 3 or 4, liver 3 or 4 , spleen 4; v) 7 month-old $\mathrm{K}$ mice: heart 2 or 3 or 4 , liver 3 or 4 , spleen 4; vi) 8 month-old $\mathrm{F}$ mice: heart 3 or 4, liver 4, spleen 4; vii) 8 month-old K mice: heart 3 or 4, liver 3 or 4, spleen 4; viii) 7 month-old Y mice: heart 0 , liver 0 , spleen 0 . All kidneys studied had a normal appearance (see explanation in Supplementary Figure S2).

Six $\mu \mathrm{m}$-thick sections of kidney, liver, heart, and spleen of $\mathrm{F}$ and $\mathrm{K}$ mice were immunostained with: (a, c) anti-hApoAII specific antibody coupled to CY2 (green fluorescence); (b) anti-human apoAII antibody/CY2 (green fluorescence) and anti-mouse apoAI (mapoAI) antibody/CY3 (red fluorescence), and viewed by confocal microscopy. Representative images are illustrated.

(a) "Early stage": a 2-month old F mouse; "Intermediate stage": a 5-6 month-old K mouse;

"Advanced stage": a 7 month-old F mouse; (b) kidney section of a 7 month-old Y mouse, devoid 
of amyloid deposits; (c) kidney sections of two 2 month-old F mice (F1 and F2, early stage); (d) kidney sections of three 7 month-old F mice (F3, F4, F5, advanced stage).

All photomicrographs contain scale bars. Arrows depict glomeruli, white arrowheads AApoAII (green), and yellow arrowheads mapoAI (red).

\section{Figure 5. Absence of amyloidosis in transgenic mice expressing normal human $A P O A 2$}

The kidneys, liver, heart and spleen were prepared from three 7 month-old transgenic F mice highly expressing STOP78SER-APOA2 and from three 7 month-old Lambda $(\lambda)$ mice highly

expressing $A P O A 2^{30,36}$. The tissue preparations are described in Methods under "Tissue sampling and biological analyses". Macroscopically, the following stages were observed: i) $\lambda$ mice: heart 0, liver 0, spleen 0; ii) F mice: heart 3 or 4, liver 3 or 4, spleen 4 . All kidneys studied had a normal appearance (see explanation in Supplementary Figure S2).

Six $\mu \mathrm{m}$-thick sections of kidney, liver, heart, and spleen of $\mathrm{F}$ and Lambda mice were immunostained with anti-hApoAII antibody (recognizing equally AApoAII and hApoAII) coupled to CY2 (green fluorescence) and viewed by confocal microscopy. Representative images are shown.

(a) Kidney; (b) Heart; (c) Liver; (d) Spleen.

All photomicrographs contain scale bars. Arrows depict glomeruli, white arrowheads AApoAII amyloid aggregates in $\mathrm{K}$ and $\mathrm{F}$ mice, and blue arrowheads hApoAII in Lambda mice.

\section{Figure 6. Electron microscopic analysis of amyloid deposits}

The kidney, liver, heart, and spleen from a 7 month-old K mouse (macroscopic stages: heart 4, liver 3, spleen 4, kidney 0), and a 7 month-old Y mouse (all macroscopic stages 0 ) were viewed by electron microscopy. Characteristic images are shown. (a) K mouse, two magnifications; (b) Y mouse, devoid of amyloid fibrils. 
Because the scale bars under the photomicrographs are very small, we added the magnifications. Arrowheads depict amyloid deposits.

Kidney: P, podocyte; PT, proximal tubule; C, capillary; MC, mesangial cell; E, endothelial cell; GBM, glomerular basement membrane; BS, Bowman space

* Characteristic image of pedicell fusion

Liver: SD, space of Disse; N, nucleus; M, mitochondrion; RER, rough endoplasmic reticulum; E, endothelial cell; SC, sinusoid capillary; G, glycogen; BC, bile canaliculus; ER, erythrocyte Heart: CM, cardiomyocyte; E, endothelial cell; M, mitochondrion; N, nucleus; PM, plasma membrane; BM, basement membrane; C, capillary

Spleen: LC1, intravascular leucocyte; LC2, extravascular leucocyte; M $\Phi$, extravascular macrophage; E, endothelial cell; C, capillary; ER1, intravascular erythrocyte; ER2, extravascular erythrocyte

\section{Figure 7. Kidney dysfunction is present in $\mathrm{K}$ and $\mathrm{F}$ transgenic mice}

Urea, creatinine, and total proteins were assayed in sera and urine of wild-type C57BL/6, F, K and Y mice. All transgenic mice were hemizygous. The protein/creatinine ratios were calculated in serum and urine, and the number of mice (n) used is shown under each genotype of the bottom graphic. The results were analyzed by the non parametric Kruskal-Wallis one-way ANOVA test. When a significant effect of the genotype on a variable was established, the non parametric Dunn's multiple Comparison test was used to compare this variable between each transgenic line and the control C57BL/6 mice. The individual data of the four variables were presented in scatter dot plots, with different colors depending on the age of the mice: green for mice under 5 months of age; yellow for mice aged between 5 and 6 months; red for mice over 6 months of age. 
Statistically significant differences between transgenic and wild-type mice are indicated by bars: $* \mathrm{p}<0.05, * * \mathrm{p}<0.01, * * * \mathrm{p}<0.001$

C57, C57BL/6 mice.

Figure 8. Decrease in serum STOP78SER-ApoAII concentration as a function of age and amyloid burden

For each mouse, STOP78SER-ApoAII was assayed twice, at age one month and upon sacrifice at ages ranging from 2 to 10.5 months. Results were expressed as mean \pm SD. Data were analyzed by the one phase decay non-linear regression. Data of $\mathrm{F}$ and $\mathrm{K}$ mice fitted the one phase decay non-linear regression model. STOP78SER-ApoAII of Y mice did not decrease with age. The number of mice used at each time point is indicated in parentheses.

Figure 9. Biochemical characterization of STOP78SER-ApoAII in HDL of patients and transgenic mice

HDL were isolated by ultracentrifugation from plasma of five patients with AApoAII amyloidosis and sera of transgenic mice. Patients carried either the STOP to Serine or the STOP to Glycine or the STOP to Arginine mutation ${ }^{10-12}$. (a) $15 \%$ SDS-PAGE and (b) Western blotting of human HDL using an anti-hApoAII antibody; (c) 15\% SDS-PAGE of HDL of hemizygous K and F mice; (d) 15\% SDS-PAGE of HDL of hemizygous and homozygous Y mice aged 5 months. The same HDL-protein amount was deposited for all samples in the same gel $(15 \mu \mathrm{g} / \mathrm{lane}$ in $\mathbf{a}, \mathbf{c}, \mathbf{d}$ and $6 \mu \mathrm{g} /$ lane in $\mathbf{b})$.

(a) Lane 1, human $\mathrm{HDL}_{3}\left(\mathrm{H}_{3}\right)$; lane 2, Sd (LMW); lane 3, purified hapoAI (AI); lanes 4 to 8, patients 1 to 5; lane 9, purified hApoAII (AII).

(b) Lane 1, Sd (LMW); lanes 2 to 6, patients 1 to 5; lane 7, purified hApoAII (AII); lane 8, HDL of Y mice carrying apoAI and STOP78SER-ApoAII. 
(c) Lane 1, HDL from Lambda $(\lambda)$ mice carrying essentially hApoAII ${ }^{30,36}$; lane 2, purified hapoAI (AI); lane 3, Sd (LMW); lanes 4 to 7, HDL from K mice aged 4, 5, 6, and 7 months, respectively; lanes 8 to 11, HDL from F mice aged 4, 5, 6, and 7 months, respectively; lane 12, Sd (LMW); lane 13, purified hApoAII (AII).

(d) Lane 1, HDL from Lambda ( $\lambda$ ) mice; lanes 2 and 3, HDL from homozygous and hemizygous Y mice, respectively; lane 4, purified hapoAI (AI); lane 5, Sd (RPN800V); lane 6, HDL from Beta $(\beta)$ mice carrying hApoAII and apoAI ${ }^{30,36}$.

The low molecular weight (LMW) standards (Sd) used were: i) LMW (Bio-Rad) corresponding, from top to bottom, to: 94, 66, 45, 31, 21.5, and $14.4 \mathrm{kDa}$; ii) RPN800V (Bio-Rad), corresponding, from top to bottom, to: $250,160,105,75,50,35,30,25,15$, and $10 \mathrm{kDa}$. vApoAII: abbreviation for variant STOP78SER-ApoAII 
Table 1. Proteomic analysis of amyloid deposits

\begin{tabular}{|c|c|c|c|c|c|c|c|c|c|c|}
\hline \multirow[b]{2}{*}{ Accession number } & \multirow[b]{2}{*}{ Description } & \multirow{2}{*}{$\begin{array}{l}\text { Gene } \\
\text { name }\end{array}$} & \multicolumn{4}{|c|}{ F mouse (MS/MS) } & \multicolumn{4}{|c|}{ Y mouse (MS/MS) } \\
\hline & & & $\begin{array}{c}\text { Kidne } \\
\mathbf{y}\end{array}$ & $\begin{array}{c}\text { Live } \\
\mathbf{r} \\
\end{array}$ & \begin{tabular}{|c|} 
Hear \\
$t$
\end{tabular} & $\begin{array}{c}\text { Splee } \\
\text { n }\end{array}$ & $\begin{array}{c}\text { Kidne } \\
y\end{array}$ & $\begin{array}{c}\text { Live } \\
\mathbf{r}\end{array}$ & $\begin{array}{c}\text { Hear } \\
t\end{array}$ & $\begin{array}{c}\text { Splee } \\
\text { n }\end{array}$ \\
\hline sp|P08226|APOE_MOUSE & Apolipoprotein E & Apoe & 27 & 45 & 19 & 156 & 0 & 1 & 0 & 0 \\
\hline sp|P29788|VTNC_MOUSE & Vitronectin & Vtn & 13 & 6 & 12 & 3 & 0 & 0 & 0 & 0 \\
\hline sp|Q06890|CLUS_MOUSE & Clusterin & $\mathrm{Clu}$ & 20 & 5 & 8 & 7 & 0 & 0 & 0 & 0 \\
\hline sp|E9Q414|APOB_MOUSE & Apolipoprotein B100 & Apob & 18 & 0 & 1 & 6 & 0 & 0 & 0 & 0 \\
\hline sp|P33622|APOC3_MOUSE & Apolipoprotein CIII & Apoc3 & 3 & 1 & 2 & 2 & 0 & 0 & 0 & 0 \\
\hline sp|Q00623|APOA1_MOUSE & Apolipoprotein AI & Apoa1 & 5 & 1 & 1 & 0 & 0 & 0 & 0 & 0 \\
\hline sp|Q02566|MYH6_MOUSE & Myosin-6 & Myh6 & 0 & 0 & 193 & 0 & 0 & 2 & 175 & 0 \\
\hline sp|Q91Z83|MYH7_MOUSE & Myosin-7 & Myh7 & 0 & 0 & 124 & 0 & 0 & 2 & 117 & 0 \\
\hline sp|A2ASS6|TITIN_MOUSE & Titin & Ttn & 0 & 0 & 108 & 0 & 0 & 0 & 129 & 0 \\
\hline sp|Q61292|LAMB2_MOUSE & Laminin subunit beta-2 & Lamb2 & 13 & 0 & 2 & 0 & 16 & 0 & 0 & 0 \\
\hline sp|P01029|CO4B_MOUSE & Complement C4-B & $\mathrm{C} 4 \mathrm{~b}$ & 16 & 0 & 0 & 0 & 2 & 0 & 0 & 0 \\
\hline sp|P68134|ACTS_MOUSE & Actin, alpha skeletal muscle & Acta1 & 13 & 3 & 39 & 4 & 15 & 6 & 36 & 10 \\
\hline sp|P57780|ACTN4_MOUSE & Alpha-actinin-4 & Actn4 & 0 & 6 & 18 & 0 & 17 & 1 & 4 & 2 \\
\hline sp|P07724|ALBU_MOUSE & Serum albumin & Alb & 4 & 7 & 4 & 30 & 7 & 2 & 3 & 1 \\
\hline sp|P01942|HBA_MOUSE & Hemoglobin subunit $\alpha$ & Hba & 2 & 2 & 2 & 30 & 5 & 2 & 2 & 9 \\
\hline sp|P20152|VIME_MOUSE & Vimentin & Vim & 23 & 1 & 5 & 0 & 17 & 0 & 0 & 4 \\
\hline
\end{tabular}




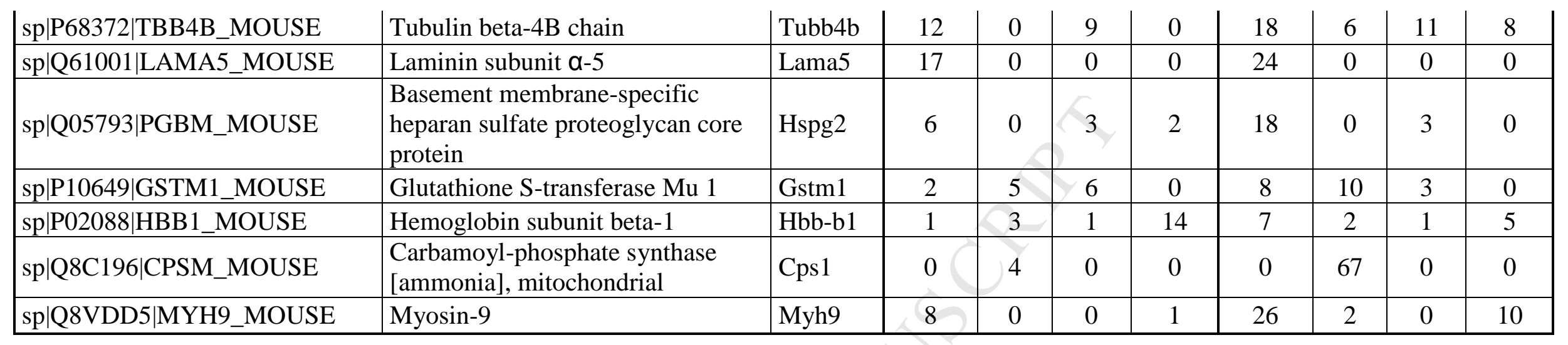

Congophilic areas of the kidney, liver, heart and spleen of one $\mathrm{F}$ and similar areas of one $\mathrm{Y}$ mouse aged 7 months were subjected to mass

spectrometry-based proteomic analysis. Proteins were identified by searching mouse SwissProt database. To identify amyloid fibril AApoAII, the sequence of the human APOA2 with the STOP78 to Serine mutation was incorporated into the database. Notably, proteins typical of a given tissue were identified in both F and Y mice (myosin-6, myosin-7, and titin in the heart; laminin subunit a-5 in the kidney).

MS/MS, number of total peptide spectra identified for each protein, corresponding to their relative abundance in the samples. 
Table 2. Increase in serum inflammation markers in transgenic mice expressing STOP78SER-APOA2

\begin{tabular}{|c|c|c|c|c|c|c|c|}
\hline & \multirow{2}{*}{$\begin{array}{c}\text { no hApoAII } \\
\text { KOAII }\end{array}$} & \multicolumn{3}{|c|}{ normal hApoAII } & \multicolumn{3}{|c|}{ STOP78SER-ApoAII } \\
\hline & & $\operatorname{BETA}(\beta)$ & $\operatorname{DELTA}(\delta)$ & $\operatorname{LAMBDA}(\lambda)$ & $\mathrm{Y}$ & $\mathrm{K}$ & $\mathrm{F}$ \\
\hline $\begin{array}{l}\text { CCL2/MCP-1 } \\
(\mathrm{pg} / \mathrm{ml})\end{array}$ & $\begin{array}{l}56 \pm 4 \\
(15) \mathrm{a}\end{array}$ & $\begin{array}{l}69 \pm 8 \\
(15) \mathrm{a}\end{array}$ & $\begin{array}{c}77 \pm 12 \\
(15) \mathrm{a}\end{array}$ & $\begin{array}{l}67 \pm 5 \\
(15) \mathrm{a}\end{array}$ & $\begin{array}{c}163 \pm 18 \\
(10) b\end{array}$ & $\begin{array}{c}170 \pm 12 \\
(30) b\end{array}$ & $\begin{array}{c}233 \pm 19 \\
(29) \mathrm{b}\end{array}$ \\
\hline $\begin{array}{c}\text { CXCL1/KC } \\
(\mathrm{pg} / \mathrm{ml})\end{array}$ & $\begin{array}{c}136 \pm 18 \\
(15) \mathrm{a}\end{array}$ & $\begin{array}{l}129 \pm 16 \\
(15) \mathrm{a}\end{array}$ & $\begin{array}{c}148 \pm 28 \\
(15) \mathrm{a}\end{array}$ & $\begin{array}{c}163 \pm 27 \\
(15) \mathrm{a}\end{array}$ & $\begin{array}{c}237 \pm 78 \\
(8) a, c\end{array}$ & $\begin{array}{l}249 \pm 31 \\
(30) \mathrm{a}, \mathrm{c}\end{array}$ & $\begin{array}{l}319 \pm 24 \\
(29) b, c\end{array}$ \\
\hline $\begin{array}{l}\text { hApoAII } \\
(\mathrm{mg} / \mathrm{dl})\end{array}$ & 0 & $\begin{array}{l}21.1 \pm 1.14 \\
\quad(13) \mathrm{a}\end{array}$ & $\begin{array}{c}43.8 \pm 4.4 \\
(12) \mathrm{a}, \mathrm{c}\end{array}$ & $\begin{array}{c}63.5 \pm 6.9 \\
(12) \mathrm{b}, \mathrm{c}\end{array}$ & $\begin{array}{l}22.5 \pm 1.6 \\
\quad(10) \mathrm{a}\end{array}$ & $\begin{array}{c}52.9 \pm 1.9 \\
(27) \mathrm{b}, \mathrm{c}\end{array}$ & $\begin{array}{r}65.2 \pm 2.6 \\
(27) b, c\end{array}$ \\
\hline
\end{tabular}

Both cytokines, hApoAII and STOP78SER-ApoAII have been assayed in the serum of fed mice. The apoAII-deficient mice (KOAII) have been described in reference 32 and the transgenic lines $\beta, \delta, \lambda$ expressing normal APOA2 in references 30 and 36 . Data are presented as Mean \pm S.E.M. with the number of mice in parentheses. All data sets were verified for Gaussian distribution. Because Bartletts's test showed that variances differed significantly, we used the non-parametric Kruskall and Wallis's one way Anova test that established a significant effect of the genotype $(\mathrm{p}<0.0001)$ on each metabolic variable (CCL2, CXCL1, hApoAII and STOP78SER-ApoAII). We then used the non-parametric Dunn's test for post-hoc multiple comparisons between groups. For each variable: two data sharing at least one letter are not statistically different; two data not sharing the same letter are statistically different (at least $\mathrm{p}<0.05$ ). 
KOAII mice, mice deficient in endogenous apoAII; CCL2, Chemokine Ligand 2, also named MCP-1, Monocyte Chemoattractant Protein 1;

CXCL1, Chemokine (C-X-C motive) Ligand 1, also named KC in mice. 


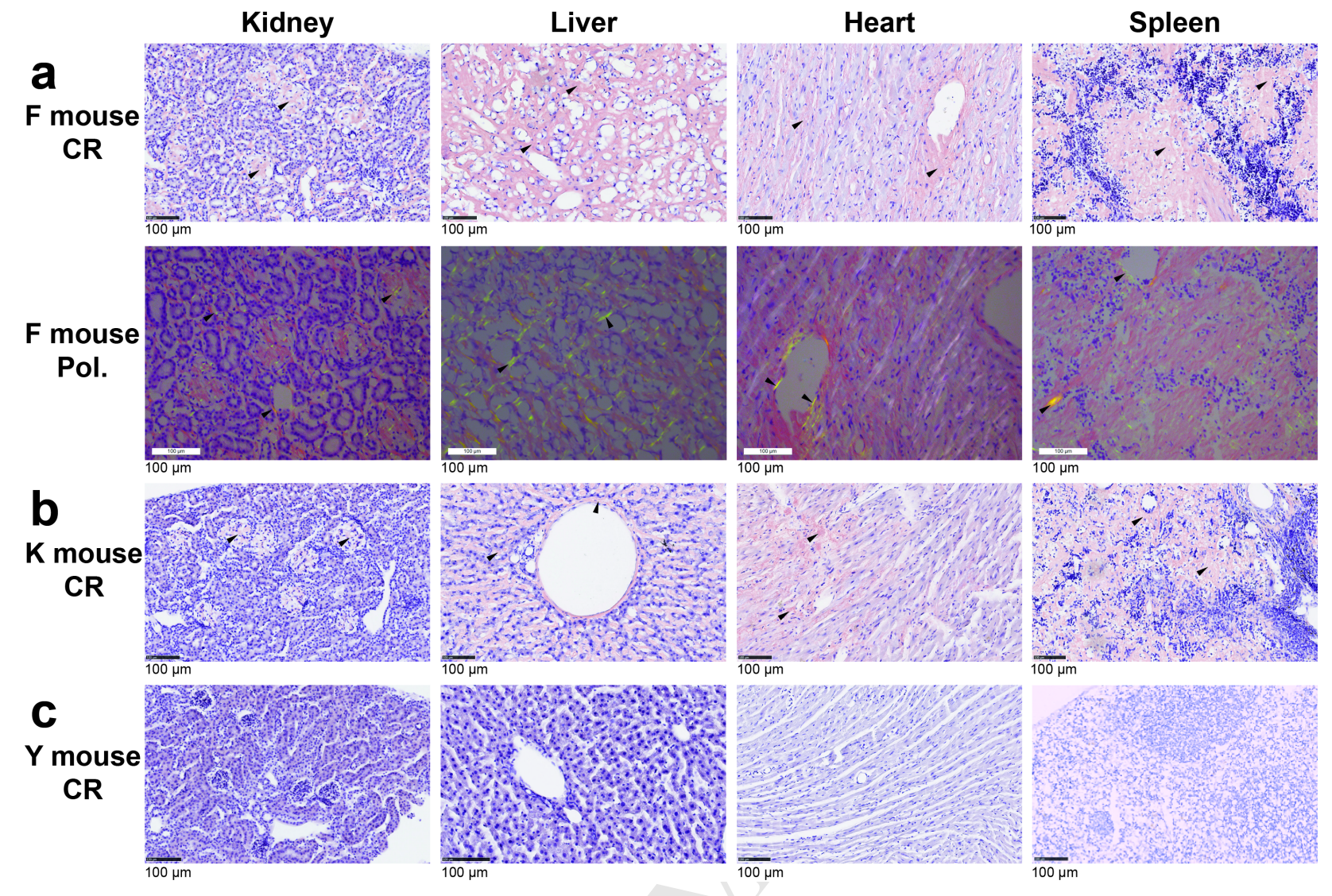


a

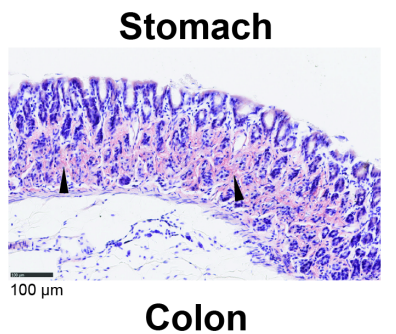

b
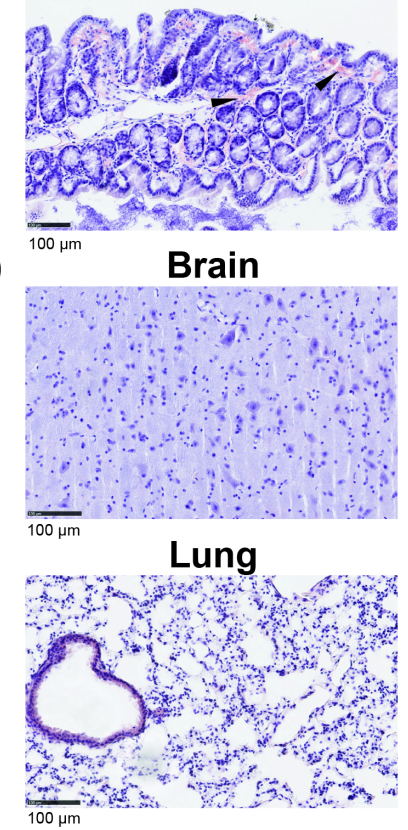
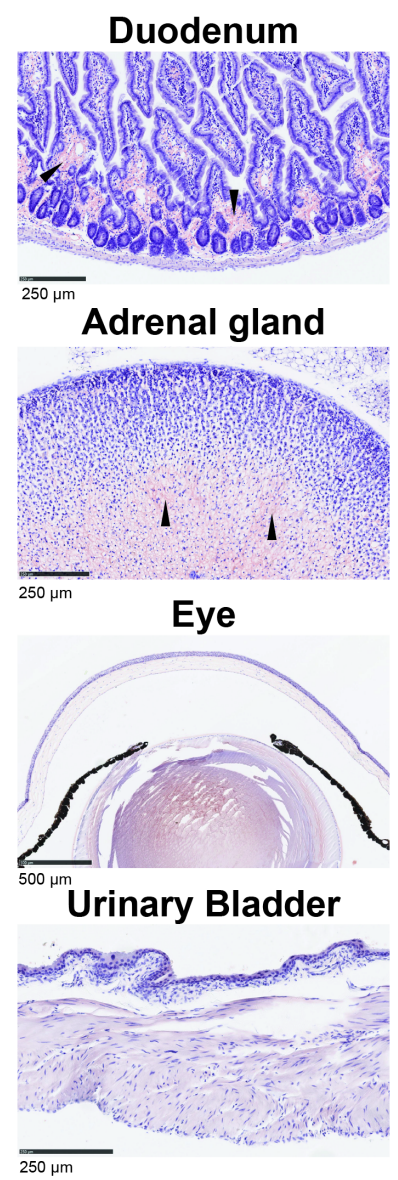
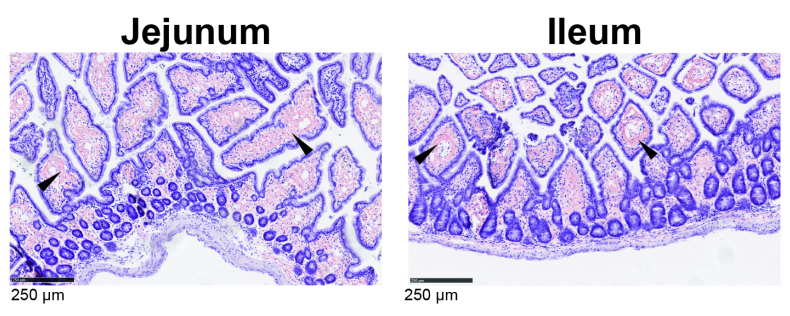

\section{Eye}
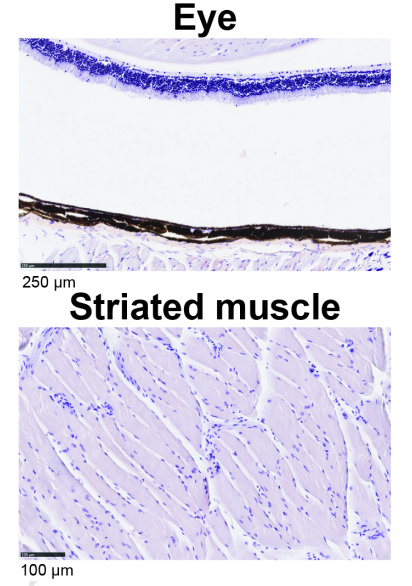

Salivary gland
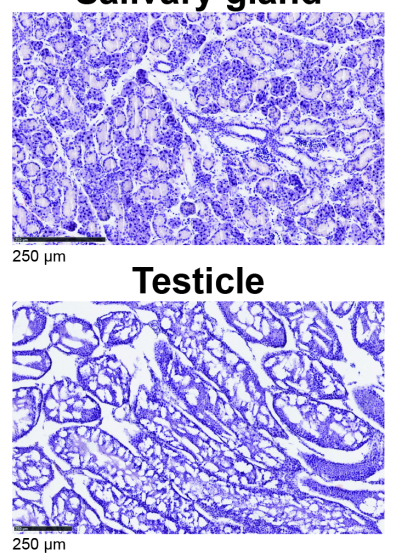


\section{Y: STOP78SER-APOA2}

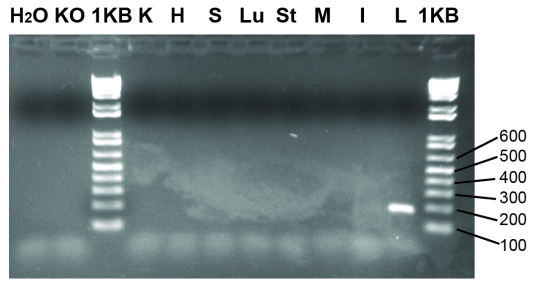

Y: BETA-ACTIN

$\mathrm{H}_{2} \mathrm{O}$ KO 1 KB K H S Lu St M I L 1KB -

Y: $18 S$ $\mathrm{H}_{2} \mathrm{O}$ KO 1KB K H S Lu St M I L 1KB 400
K: STOP78SER-APOA2

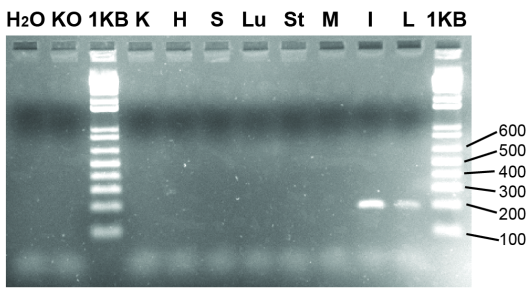

$\mathrm{K}$ : BETA-ACTIN

$\mathrm{H}_{2} \mathrm{O}$ KO 1KB K H S Lu St M I L 1KB 三 -

$\mathrm{K}: 18 \mathrm{~S}$

$\mathrm{H}_{2} \mathrm{O}$ KO $1 \mathrm{~KB}$ K $\quad \mathrm{H} \quad \mathrm{S}$ Lu St M I L 1KB 400

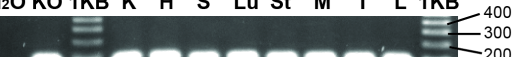

F: STOP78SER-APOA2

$\mathrm{H}_{2} \mathrm{O}$ KO 1KB K H S Lu St M I L 1KB

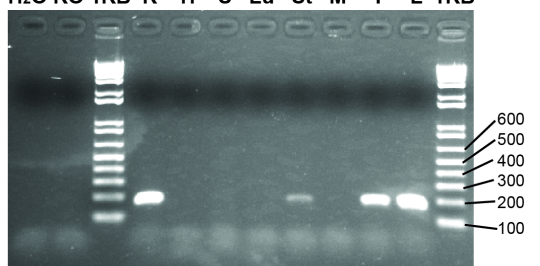

F: BETA-ACTIN

$\mathrm{H}_{2} \mathrm{O}$ KO $1 \mathrm{~KB} K$ H S Lu St M I L 1KB 三 - - - - - - - - - $=<^{200}$

F: $18 S$ $\mathrm{H}_{2} \mathrm{O}$ KO 1 KB K $\quad$ H $\quad$ S $\quad$ Lu St M I L 1 KB $Z_{300}^{400}$ 

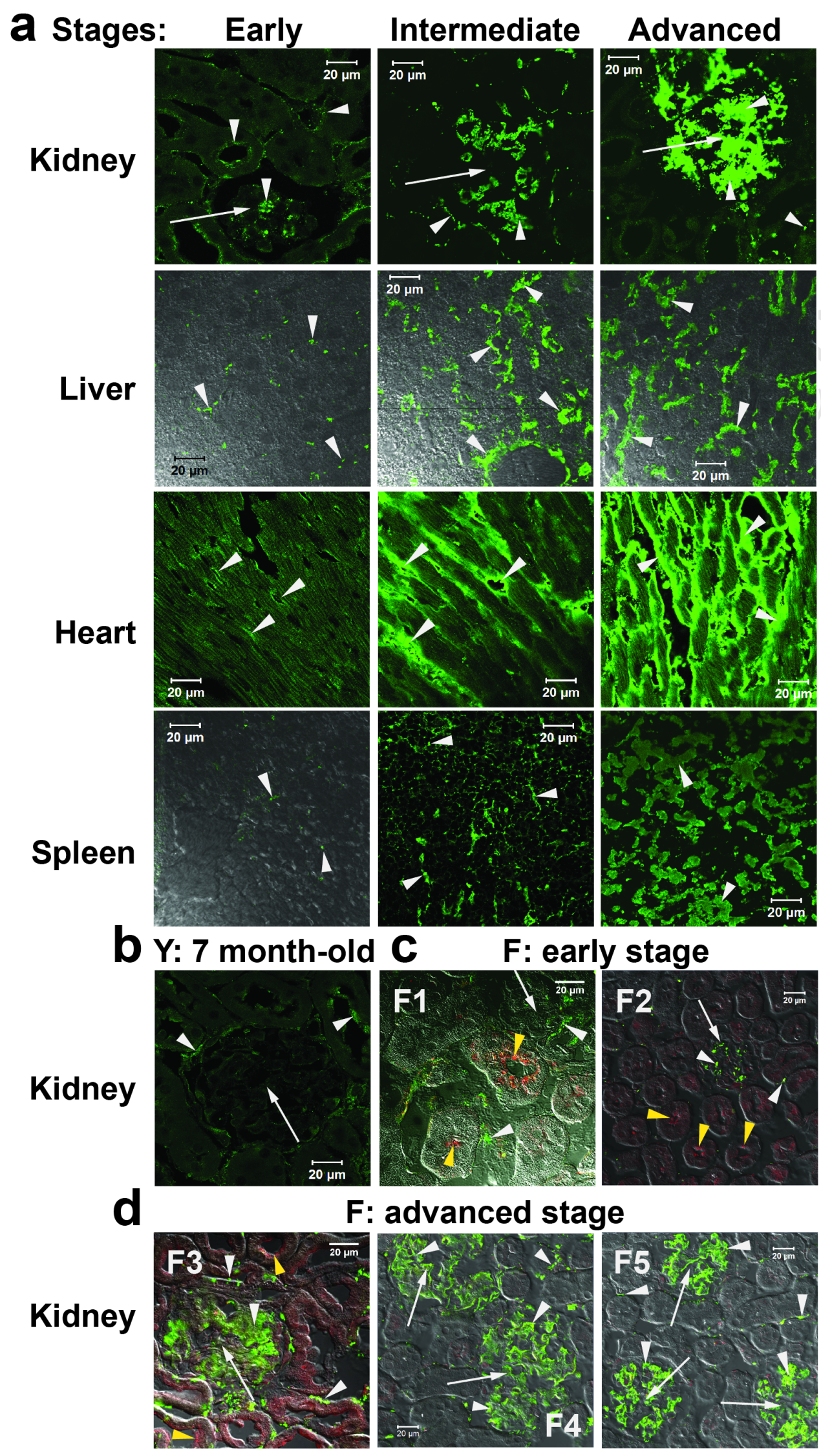

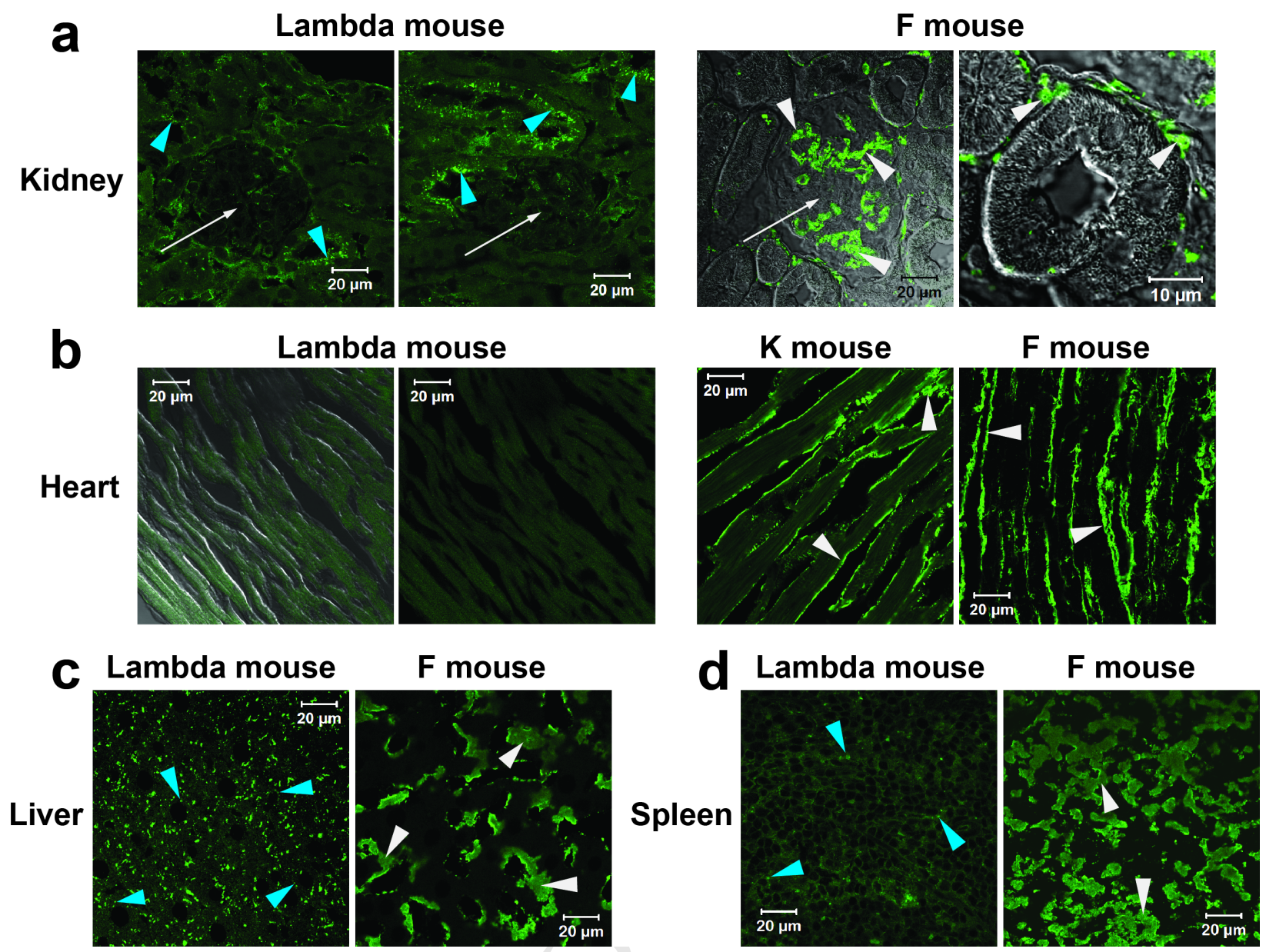

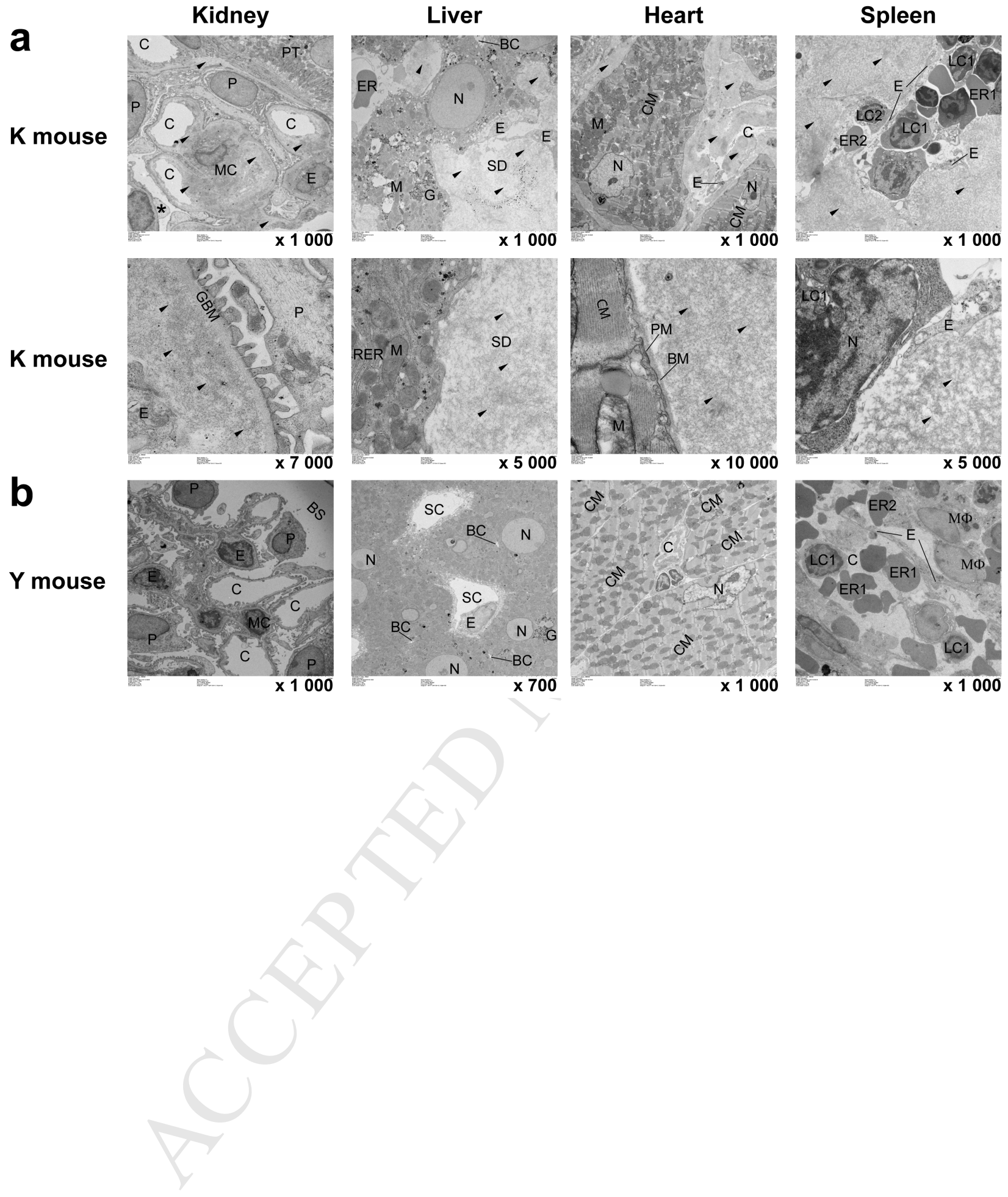
Serum
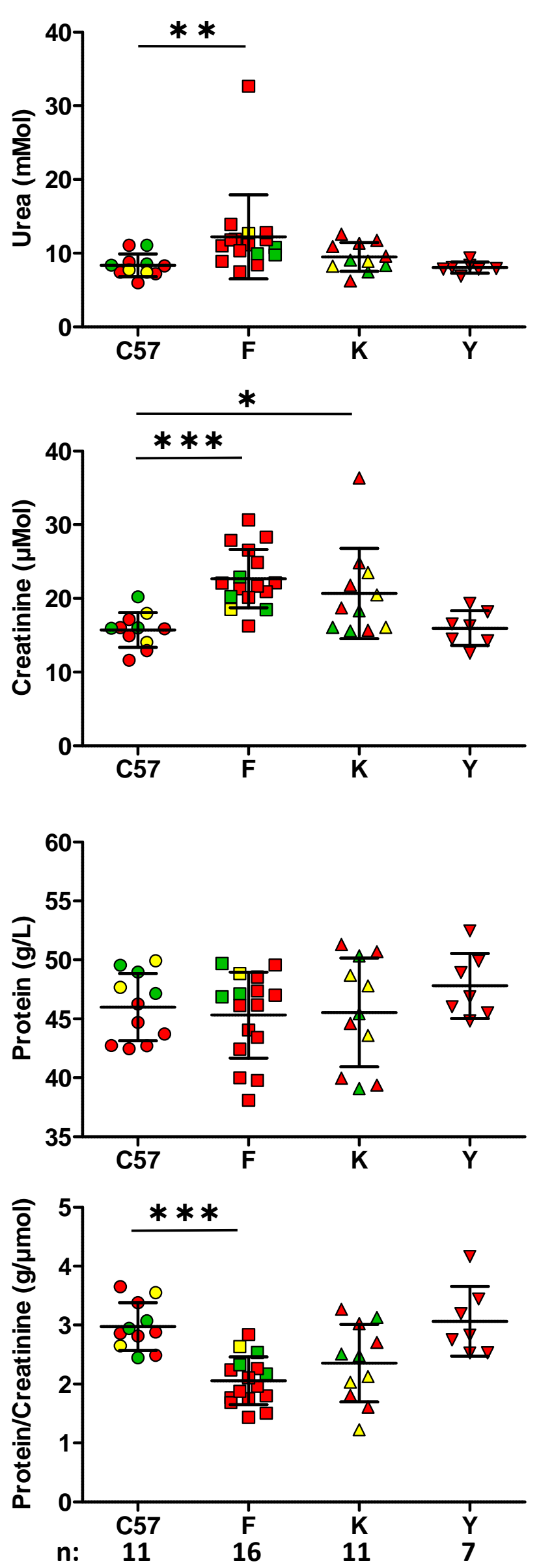
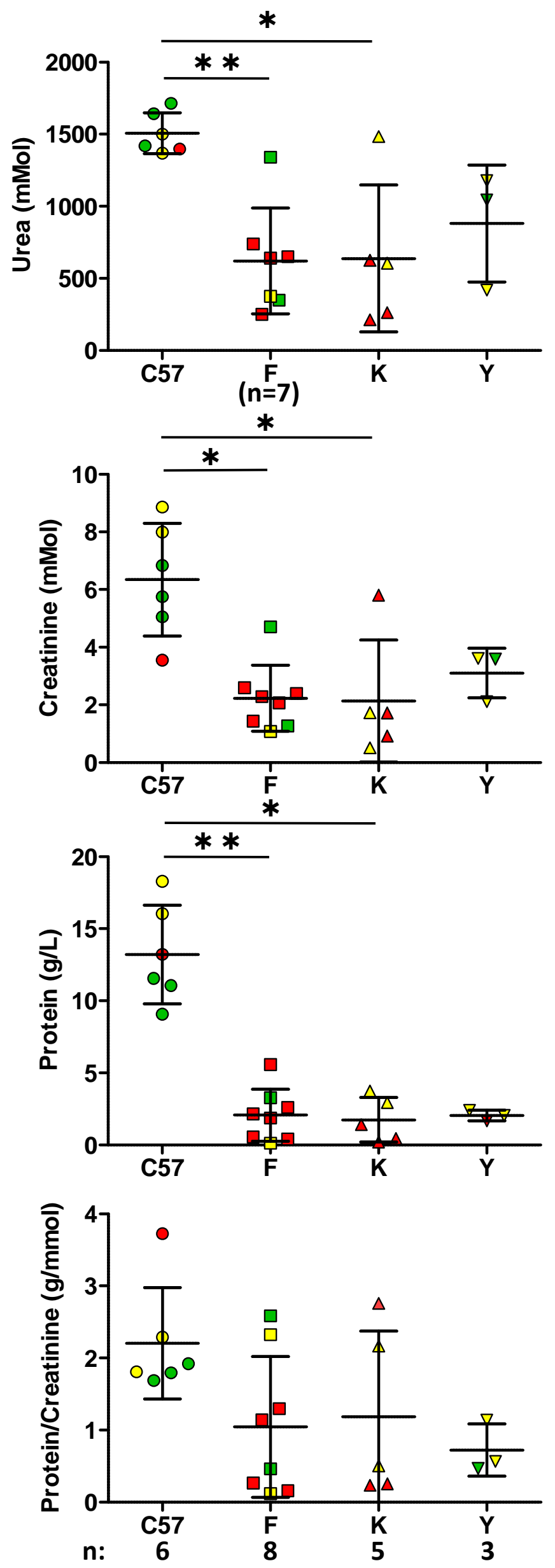

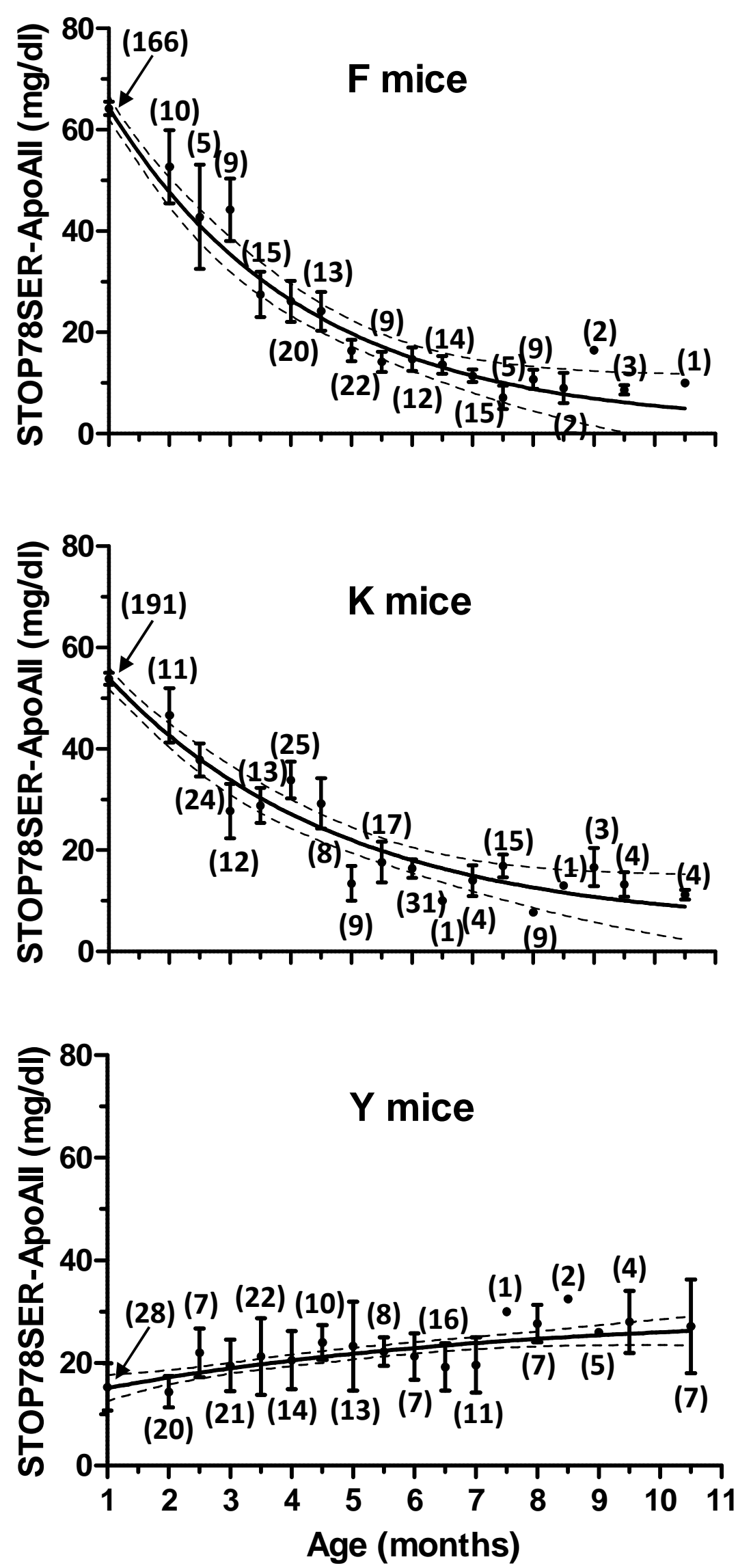


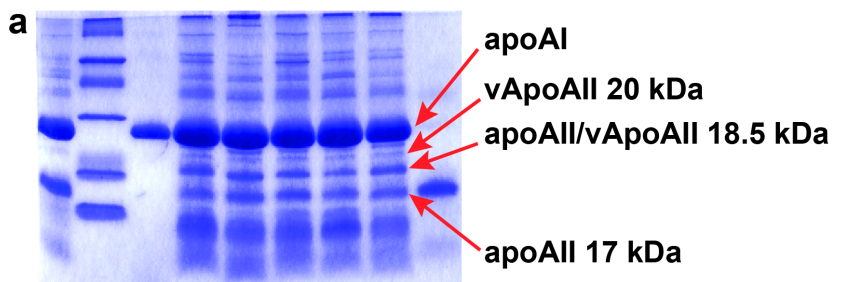

$\begin{array}{llllllll}\text { H3 Sd Al } & 1 & 2 & 3 & 4 & 5 & \text { All }\end{array}$ b

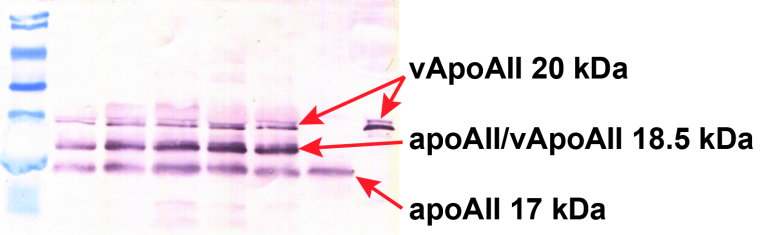

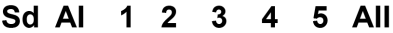

C

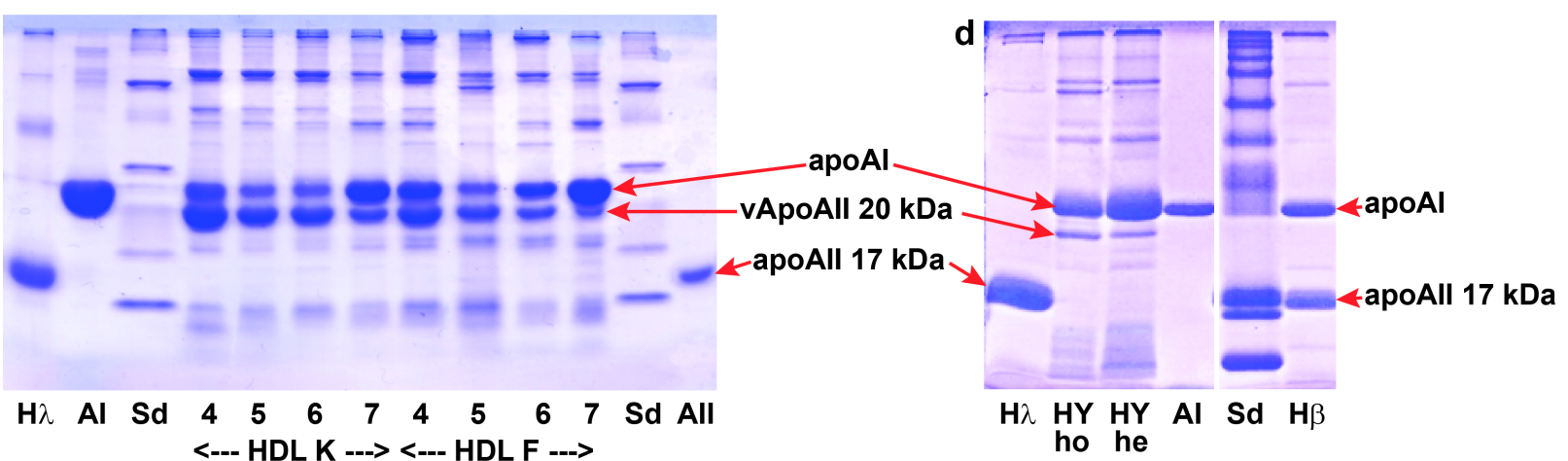




\section{A transgenic mouse model reproduces human hereditary systemic amyloidosis}

Transgene: vApoAll the amyloidogenic variant of human apolipoprotein All with the STOP $\rightarrow$ Ser mutation

Transgenic lines:

Spontaneous development of amyloidosis as a function of vApoAll expression level and age of the mice

8\% high expression:

F onset at 2-3 months normal expression: K onset at 3-4 months low expression

\section{Amyloid deposits in kidney glomeruli cause kidney dysfunction}

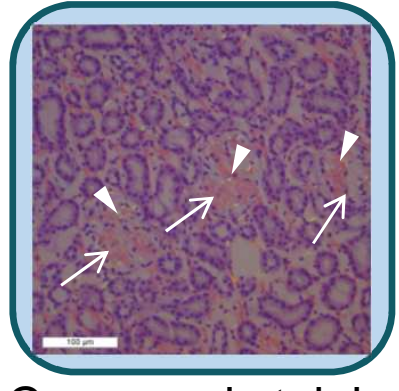

Congo red staining (polarized light)

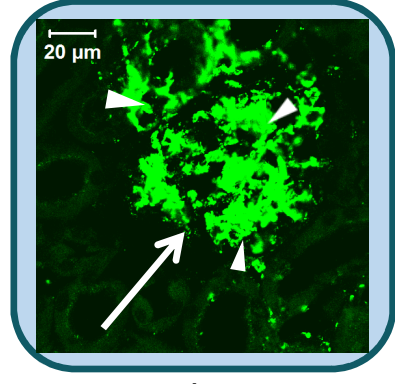

vApoAll (immunohistochemistry)

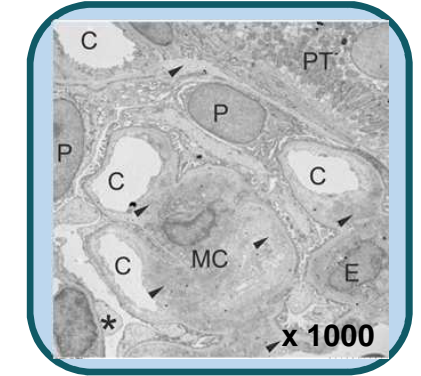

Electron microscopy

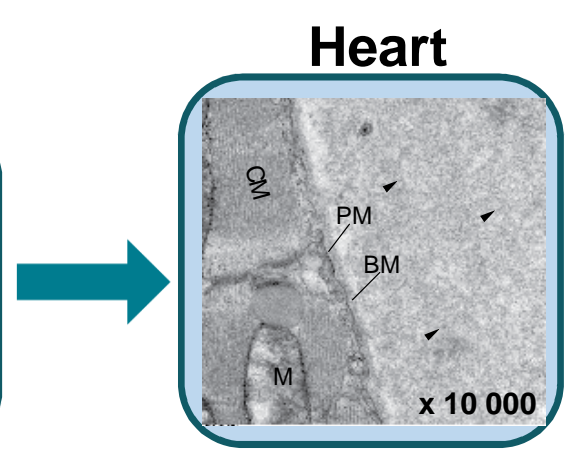

Arrows: glomeruli

Arrowheads:

amyloid deposits

\section{Systemic amyloidosis:}

vApoAll, produced by liver and intestine, forms amyloid deposits in most organs (shown: heart, spleen)

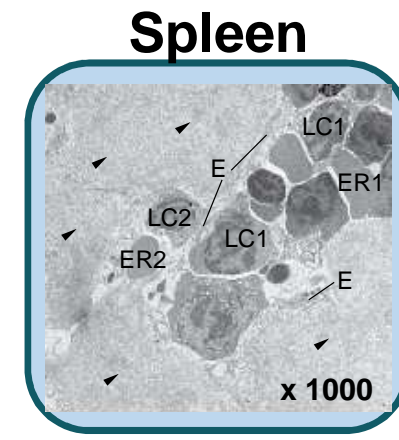

\section{No amyloidosis}

\section{CONCLUSION:}

Novel transgenic model, ideally suited to devise and test novel therapies for hereditary systemic amyloidoses 